\title{
AFROARIQUEÑOS: CONFIGURACIONES DE UN PROCESO HISTÓRICO DE PRESENCIA
}

\author{
Giselle I. Duconge y Menara Lube Guizardi²
}

\section{* Introducción}

Resumen

El objetivo del presente texto es recuperar y narrar los procesos históricos de la presencia afrodescendiente en la ciudad de Arica, norte de Chile. Más allá de la intención de construir un relato histórico que abarque la totalidad del fenómeno, nuestra narración está orientada a subrayar puntos de la historia afroariqueña que permitan dar sentido al actual proceso de lucha por el reconocimiento que diferentes colectivos afro-descendientes vienen protagonizando en los últimos años en la ciudad. Partimos contextualizando el tráfico de africanos en América Latina, apuntando las características generales del fenómeno en la región. Luego, contextualizamos la presencia de los esclavos negros en el Virreinato del Perú, territorio político al que pertenecía Arica, explicando las principales rutas de llegada, etnias y los usos de esta mano de obra africana. Finalmente, hablaremos de las configuraciones de la presencia afrodescendiente actualmente en la ciudad, especificando algunos aspectos generales sobre su movimiento para el reconocimiento de una etnicidad afrochilena.

Palabras claves: esclavitud africana - diáspora - Arica - colonialismo reconocimiento étnico.

The aim of this work is to recover and narrate the historical processes regarding the Afro-descendent presence in Arica, a city of Northern Chilean territory. Beyond the intention to build a historical narrative that covers the whole phenomenon, the paper is oriented to highlight aspects of the Afro-Arican history that could help to understand the movements for ethnic recognition that these collectives are articulating nowadays. We start contextualizing the African slavetrade to Latin America, describing the general characteristics of this phenomenon in the region. Afterwards, we will contextualize the presence of black slaves in the Viceroyalty of Peru, to which Arica used to belong. Finally, we will conclude debating some aspects about the Afro-Descendent movements nowadays in the city, specifying their petition for the recognition of an Afro-Chilean ethnicity.

Key words: African slavery - diaspora - Arica - colonialism ethnic recognition.

Recibido: diciembre 2013. Aceptado: octubre 2014.
El presente artículo constituye un esfuerzo inicial por comprender la organización comunitaria de los colectivos afrodescendientes de Arica, ciudad fronteriza en el extremo norte de Chile. Justamente por ello, los debates que aquí llevaremos a cabo devienen de (y deben ser entendidos como) un proceso aún en marcha: planteados para incitar nuevos interrogantes, nuevos posicionamientos en cuanto a la mirada a tener, más que para ser tomados como aportes concluyentes sobre la temática. Cuando nos referimos a que se trata de un primer paso, de un esfuerzo inicial, lo hacemos con un sentido teórico y metodológico específico, que nos hace centrar nuestras reflexiones en la necesaria constitución contextual -y terminantemente histórica- que conforma y delinea los fenómenos sociales observados a tiempo presente.

Con esto nos referimos a que nuestro proceso de investigación tiene un carácter antropológico y está centrado en un movimiento político actual: indaga a partir de la etnografía en la forma cómo los colectivos afroariqueños vienen enunciando su lucha en pos del reconocimiento formal de la etnicidad afrochilena. Pero, por otro lado, nuestro punto de partida ha debido reconstruir el sentido histórico con que miramos la constitución tanto de esta presencia afrodescendiente en el extremo norte chileno, como también la enunciación de su demanda por reconocimiento étnico.

En términos metodológicos, nuestro trabajo deviene de un proceso interdisciplinario que hace confluir dos

\footnotetext{
1 Programa de Doctorado en Antropología UCN-UTA. Instituto de Investigaciones Arqueológicas y Museo R.P. Gustavo Le Paige s.j. (IIAM), Universidad Católica del Norte. Gustavo Le Paige 380, San Pedro de Atacama, CP 1410000, CHILE. Email: ginvernon@ucn.cl

2 Departamento de Antropología, Universidad Alberto Hurtado; Instituto de las Migraciones, Etnicidad y Desarrollo Social (IMEDES, España).Almirante Barroso 10, Santiago, CP 6500620, CHILE. Email: mguizardi@uahurtado.cl
} 
estrategias de investigación. Por un lado, la revisión historiográfica, realizada entre agosto de 2012 y noviembre de 2013, y desarrollada no solamente a partir del estudio de las investigaciones académicas disponibles, sino también a partir de la revisión de documentos y archivos históricos de la Biblioteca de la Universidad de Tarapacá (Arica, Chile) y de los textos publicados por las organizaciones sociales afroariqueñas.

Por otro lado, nuestra estrategia metodológica involucró la experiencia etnográfica que llevamos a cabo desde mayo de 2013 junto a tres organizaciones sociales: Oro Negro, Lumbanga e Hijas de Azapa. Además de la observación de actividades colectivas (fiestas, movilizaciones, lanzamiento de libros) de las mismas, realizamos una serie de 18 entrevistas en profundidad con miembros de estas agrupaciones. Las entrevistas estuvieron centradas en indagar sobre la trayectoria de vida de los sujetos, a la vez que buscaban entender las formas cómo estos movimientos se habían organizado, las principales demandas que enunciaban, y su postura en relación a los modos de comprender la identidad afroariqueña.

La decisión de iniciar una etnografía a través un proceso de investigación historiográfico nos remite a consideraciones de carácter teórico sobre la construcción de la mirada antropológica. Con Comaroff y Comaroff (1992: 6-7), comprendemos que historizar la etnografía es un recurso obligado si lo que pretendemos es evitar reproducir "cosmologías racionalistas" (y etnocéntricas) que reifican el logos del investigador como nexo explicativo de las causalidades del fenómeno que éste "observa". Por otro lado, este tipo de cuestionamiento sobre la mirada antropológica nos sitúa en un esfuerzo de superación de aquello que Fabian (2014) entiende como la bipolaridad sincronía-diacronía naturalizada en el método etnográfico. De nuestra parte, hemos traducido este intento de superación a modo de un énfasis teórico y empírico en la constitución del movimiento afroariqueño como una configuración cultural.

Según Grimson (2011: 172) el concepto de configuración cultural "enfatiza la noción de un marco compartido por actores enfrentados o distintos, de articulaciones complejas de la heterogeneidad social". Cuatro serían los elementos constitutivos de una configuración cultural. Por un lado, ellas son campos de posibilidad: se refieren a las instituciones, representaciones y prácticas que en determinado contexto son posibles o imposibles, y aquellas que devienen hegemónicas. En segundo lugar, las configuraciones culturales suponen que, en dado contexto, las acciones, formas de ser y enunciar, relaciones, experiencias y conocimientos guardan algún nivel de interrelación entre sí, pero esto no deriva en una homogeneidad constitutiva. La configuración cultural sería así, doblemente, heterogénea y heterotópica (Grimson 2011: 176). A su vez, y en tercer lugar, la configuración cultural, para ser articulada, requiere de una trama simbólica común, que permita vincular, aunque heterogéneamente, la cuarta dimensión de la configuración: el que ella resguarda, aun cuando asimétricamente, algo que es común y compartido (Grimson 2011: 177). Lo que buscaremos hacer en los subsecuentes apartados del texto es, justamente, subrayar elementos históricos que constituyen (a la vez que posibilitan) la emergencia en tiempo presente de estas cuatro dimensiones de configuración cultural vinculadas al movimiento afroariqueño.

Así, aunque consideramos la historicidad de los grupos estudiados inabarcable como totalidad, ${ }^{3}$ entendemos que es imprescindible dilucidar el posicionamiento de nuestra mirada sobre el sentido histórico del fenómeno. Con esto buscamos, al mismo tiempo, situar los sujetos en su proceso histórico, y situar nuestra mirada como un elemento que recorta, altera e interpreta este mismo proceso. Se tratarían así de dos formas diversas de historicidad que se encuentran asimétricamente. Observados y observadores son entendidos aquí como constructores de prácticas que, incluso cuando intercambiables, son ubicadas en configuraciones históricas particulares.

\footnotetext{
3 La construcción de un relato histórico que abarcara la totalidad del fenómeno nos parece metodológica y epistemológicamente improbable. Comprendemos que los fenómenos históricos son siempre complejos y multideterminados en sus elementos constitutivos, de manera que su reconstrucción requiere siempre un recorte previo del investigador, quien obligadamente selecciona los elementos que incluirá en su cadena de sentido de la historia. Por esto, la recuperación del sentido histórico implica constituir causalidades que no pueden postularse como una relación entre la totalidad de fenómenos históricos de un instante dado y de aquel que lo precede. La reconstrucción del sentido histórico es siempre parcial y elaborada a partir de los elementos de conformación del mismo sujeto histórico que lo ejecuta, en este caso, los investigadores (Aron 2000: 459).
} 
Este debate resulta fundamental como punto de partida para el presente trabajo, en la medida en que sintetiza una postura crítica que sirve como hilo conductor del debate. Esto se refiere a la necesidad de desarrollar una historización del mismo argumento de reconocimiento étnico de los movimientos afroariqueños, mirándolos como parte de un proceso histórico en el que la identidad racial y luego étnica ha estado presente de diferentes maneras, transitando hacia enunciaciones que han dialogado con la construcción colonial y luego nacional de las identidades sociales en la localidad de Arica.

Partiendo de estos supuestos, nuestra mirada histórica centraliza particularmente tres momentos de la conformación de la presencia afro en la ciudad de Arica: aquel que remite al proceso de colonización española, aquel que remite a la conformación de los Estados-nacionales (Perú y Chile) en la zona, y aquel que remite a la chilenización de Arica a partir de 1883. La razón por la que nos centramos en estos tres puntos -y no en otros- se refiere a nuestra percepción de que ellos juegan un rol central en la constitución de la relación entre las identidades (nacionales, étnicas y raciales), formas de ser y de estar y asignaciones de pertenencia en Arica. Entendemos que ellos son cruciales para comprender la forma como los paradigmas étnicos (Segato 2007) ${ }^{4}$ fueron desarrollados en Arica haciendo confluir en la localidad unas particulares experiencias de la identidad.

A partir de estos tres momentos históricos, subrayaremos elementos que permitan dar sentido al actual proceso de lucha por el reconocimiento que diferentes co-

4 Según Segato (1999 y 2007) las categorías étnico, etnicidad y sus variantes fluyen en el marco de las naciones y son usadas como fundamentos que soportan el racismo colonial que persiste, permaneciendo como paradigmas reduccionistas de una ciudadanía de segunda clase, subordinada y adscripta, a manera de minorías culturales recién llegadas a la "nación imaginada". La construcción del Estado Moderno en América Latina, sobre todo tras las independencias, ejecutó una forma mitológica de centralización de la identidad, que requirió no solamente la construcción de las fronteras nacionales marcadas euclidianamente sobre el territorio. Requirió también la invención de fronteras de adscripción étnica, cultural e incluso biológica entre los que pertenecen y los que no pertenecen a la nación. Esta última reprodujo los ideales de auto-representación de las elites nacionales en América Latina, desarrollando un paradigma de la etnicidad que da sentido a la identidad nacional que excluye a las poblaciones y minorías presentes en el territorio. lectivos afrodescendientes vienen protagonizando en la localidad. En este sentido, y aunque sin pretensiones totalizadoras, nuestro argumento se construirá siguiendo un orden que va de lo general a lo específico. Partiremos contextualizando el tráfico africano en América Latina, apuntado las características más amplias del fenómeno en la región. Luego, contextualizamos la presencia de los esclavos negros en el Virreinato del Perú, territorio político al que pertenecía la ciudad de Arica, explicando las principales rutas de llegada, etnias y los empleos dados a esta mano de obra africana. Hablaremos además de la situación de los descendientes de esclavos africanos en Arica tras la Guerra del Pacífico (1879-1883), contexto histórico que marca el largo período de transición de la ciudad a la geografía nacional chilena.

Los dos apartados finales del texto se centran en las experiencias afroariqueñas actuales, en la conformación de asociaciones populares. Hablaremos de las configuraciones de la presencia afrodescendiente actualmente en la ciudad, especificando algunos aspectos generales sobre su lucha, y sobre su posible significado como proceso de reconocimiento de la etnicidad afrochilena. Asimismo, hacemos hincapié en que nuestro aporte hacia el análisis etnográfico del fenómeno es incipiente y que lo que proponemos no es más que el paso previo a este mismo análisis: el giro de mirada que permite historizar nuestras indagaciones sobre el fenómeno.

\section{* Configuraciones de la presencia africana Y DEL RACISMO EN AMÉRICA LATINA}

El actual sistema-mundo se configura como un proceso geopolítico global que tiene su inicio con los viajes de "descubrimiento", con la colonización de las Américas y con la esclavitud africana, a partir del siglo XVI. La realidad social en que vivimos no es la de los múltiples Estados nacionales, sino que de un algo mayor, del que los Estados son parte integrante. ${ }^{5}$ Esta visión de los procesos

5 En este sentido, se postula que este sistema-mundo cuenta y ha contado con "muchas instituciones, Estados y sistemas interestatales, compañías de producción, marcas, clases, grupos de identificación de todo tipo y que estas instituciones forman una matriz que permite al sistema operar pero al mismo tiempo estimula tanto los conflictos como las contradicciones que calan en el sistema" (Wallerstein 2006: 10-11). 
históricos de los Estados en su interconexión tensiona el supuesto de una contención fronteriza euclidiana de lo nacional y permite comprender la múltiple determinación de los fenómenos locales en el marco del surgimiento de la modernidad y también de su actual "desborde" (Appadurai 2004), con la aceleración del capitalismo y con la globalización. Permite, simultáneamente, elaborar de manera crítica la relación intrínseca entre los procesos coloniales en América Latina y Caribe y el paralelo "desarrollo" de los países del norte global que, no por casualidad, constituyeron en su mayoría las metrópolis coloniales.

En esta línea, la comprensión de la dimensión e importancia del tráfico en América Latina debería ser entendida desde perspectivas que subrayen su transversalidad como fenómeno político y económico, reconociendo la centralidad del comercio de esclavos africanos y de la explotación violenta de su mano de obra, como formas sine qua non del colonialismo (Fontaine 1980: 111-112). Este proceso impacta la constitución del sistema mundo (Wallerstein 2006: 10) en dos dimensiones que resultan fundamentales aquí: 1) imprimiendo en Latinoamérica una serie de estructuras sociales, culturales y económicas que reproducen la explotación africana hasta la actualidad; y 2) constituyendo en el continente europeo las marcas del proceso económico de acumulación que potenciará, siglos después, las revoluciones industriales, así como su constitución en cuanto "centro" (Dussel 1994) de un nuevo modo productivo.

De la mano de Gilroy (2002: 43-48) podríamos decir que, a pesar de que gran parte de la historiografía internacional no lo haya reconocido como tal, la recaudación de capitales permitidos por las "industrias esclavistas" constituyó una de las formas primordiales de la acumulación capitalista, siendo uno de los prerrequisitos para el desarrollo de la revolución industrial e incluso para la construcción del iluminismo europeo. ${ }^{6}$

\footnotetext{
$\overline{6}$ Este debate aparece ya en Marx (1996), quién reconoce los elevados niveles de violencia del proceso de acumulación primitiva del capitalismo y su vinculación con la colonización y esclavitud africana. El autor postula, además, que estos hechos fueron sistemáticamente invisibilizados por la historiografía y la economía política decimonónicas, que han representado el nacimiento de la era capitalista como un proceso "idílico": "la transformación de África en un campo cercado para la caza comercial a las pieles negras marca la aurora de la era capitalista de producción" (Marx
}

El sistema colonial imprimió, a través de la esclavitud africana y de la explotación de las poblaciones indígenas locales, dos formas jerarquizadas e interconectadas de control y dominio racial-social en América Latina. Por un lado, se institucionaliza una jerarquía racial que en las colonias latinoamericanas conforma y consolida la explotación de los negros e indígenas, justificando a partir de la ideología racista su supuesta inferioridad. Por otro lado, se consolida también una jerarquía racial global, que marca la diferencia entre la supuesta composición racial de Europa y Norteamérica -presumidamente blanca-y la composición del mundo colonizado: mestizo, negro, indígena. Estas dos mitologías se encuentran y confunden con el proceso de institucionalización de los Estados-nacionales ya a fines del siglo XVIII, lo que implica pensar la trascendencia política del racismo como forma ontológica de clasificación de los "otros latinoamericanos" y como estructura fundamental del Estado democrático moderno.

El mito moderno de la homogeneidad nacional interna, como trazo inequívoco de las naciones y de su unidad y control político, dejó marcas muy fuertes en los Estados europeos desde la revolución francesa, habiéndose expandido como ethos político en América Latina sobre todo tras las independencias. ${ }^{7}$ Entre 1870 y 1914 los mitos de la homogeneidad racial se naturalizan entre los Estados-nacionales, fundando una idea de ciudadanía equivalente a una concepción de raza y de nacionalidad (Hobsbawm 1997: 117). La homogenización de la población nacional bajo la pretendida unicidad de una raza común (de una biología común) está fuertemente vinculada a esta presión de control último de los ciudadanos como forma biológica que pertenece a la nación: como la forma

\footnotetext{
1996: 370). Para un análisis sobre la importancia del esclavismo africano en América Latina en la composición de acumulación primitiva en el capitalismo moderno, véase el trabajo clásico de Ianni (1978).

7 La centralización de los Estados-naciones europeos a partir de fines del siglo XVIII obligó a la supresión de las diferencias culturales internas (Hobsbawm 1997: 114), forjando la ideología de que la unidad de la nación sobre un territorio (circunscrito por unas fronteras euclidianamente dibujadas) ocurría gracias a una unidad lingüística, étnica, racial, religiosa, artística, social y política (Hastings 2000: 14). Para llegar a esa unidad tuvo que ser ejecutada mucha violencia contra la pluralidad interna de las recién inventadas naciones (Appadurai 2006: 3; Hastings 2000: 18).
} 
viva prioritaria del proyecto de centralización política nacional. ${ }^{8}$ En el fondo histórico de los nacionalismos y del racismo existen problemas de poder, ideología y política que no se pueden entender únicamente como factores "de orden cultural" (Hobsbawm 1997: 120).

El colonialismo, en el marco del sistema mundo -como forma operante de una geopolítica y economías globales- se ha reproducido hasta la actualidad a través de las jerarquías raciales (Walsh 2004: 333). Éstas persisten a modo de colonialismo interno ${ }^{9}$ en las ex-colonias, aún cuando el colonialismo casi se haya extinguido en términos jurídicos (con la independencia ratificada a niveles formales) (Grosfoguel 2006: 61); y aún cuando en la esfera global el uso del término raza como definidor de grupos o prácticas sociales se haya asumido como políticamente incorrecto (Casaús-Arzú 2006).

De esta manera, la invisibilidad que en ciertas áreas de América Latina se ha dado a la influencia e importancia de la presencia africana en el marco de los procesos económicos -primero coloniales, luego nacionales- remite a la reproducción, en las esferas del pensamiento y de las ciencias sociales, de las jerarquías de raza que componen un elemento estructurante de las relaciones de poder en este contexto regional y en el sistema mundo. En este sentido, la negativa en asumir el papel central de africanos y africanas en la composición del "nuevo mundo" remite a la "estructura y distribución del conocimiento en las Américas, que es en cambio un reflejo de la estructura y distribución de la riqueza, poder y status en la región"

8 De ahí la necesidad de pensar la dimensión política del concepto de raza, lo que nos permitiría "situar el racismo desde el Estado, no solo como una ideología de la diferencia y de la desigualdad; no solo como forma de dominación y opresión entre grupos étnicos, sino como una lógica del exterminio y de la exclusión, como una tecnología del poder" (Casaús-Arzú 2006: 11).

9 Aquí reincidimos en las reflexiones de González (2003: 3), para quién: "el colonialismo interno está originalmente ligado a fenómenos de conquista, en los que las poblaciones de nativos no son exterminadas y forman parte, primero del Estado colonizador y después del Estado que adquiere una independencia formal, o que inicia un proceso de liberación, de transición al socialismo, o de recolonización y regreso al capitalismo neoliberal. Los pueblos, minorías o naciones colonizadas por el Estado-nación sufren condiciones semejantes a las que los caracterizan en el colonialismo y el neocolonialismo a nivel internacional".
(Fontaine 1980: 111). ${ }^{10}$ Corregir esta asimetría resulta fundamental no solamente en el sentido de redimensionar los procesos de exclusión social a los que diferentes grupos están expuestos (Bello y Rangel 2002), sino que también implica un importante movimiento de cuestionamiento de la colonialidad del saber. ${ }^{11} \mathrm{La}$ distorsión de la importancia de la presencia africana en lo que se refiere a la comprensión de la construcción político-económica de América Latina y del Caribe es, simultáneamente, un problema a ser pensado desde la sociología del conocimiento (Fontaine 1980: 112), puesto que implica repensar la forma como la categoría de desigualdad social y discriminación racial se plasman y se reproducen en las esferas académicas (Restrepo 2004; Walsh 2004).

Con todo, la historia del tráfico africano hacia las Américas es difícil de rastrear y aún más difícil de cuantificar (Eltis 2001; Lovejoy 1982). Esto remite directamente a las características de la actividad: al modus operandi de la industria del saqueo, piratería y de la guerra que permitió la institucionalización -por parte de las más importantes naciones europeas- del comercio humano de personas retiradas de África. ${ }^{12}$ Los registros eran imprecisos, en parte debido al hecho de que al lado de la "industria formal" de la esclavitud, se desarrollaba la industria del comercio ilegal de africanos, tan o más lucrativa que la primera. Esta segunda, debido a sus particulares características contraventoras, ha dejado poco o ningún registro. Lo que sí se estima es que el primer navío transportando esclavos africanos a las Américas

\footnotetext{
${ }^{10}$ Bello y Rangel (2002: 40) concuerdan con esta percepción cuando afirman que, en América Latina y el Caribe, aún hoy en día, “el origen étnico racial influye de manera importante en la posición que ocupan las personas dentro de la estructura social, siendo la discriminación y la exclusión los mecanismos a través de los cuales un grupo dominante mantiene y justifica la subordinación social y económica de otros, reproduciendo y perpetuando la inequidad".

${ }^{11}$ Comprendida esta última como la constitución de una epistemología, de categorías y estructuras del conocimiento que reproducen los regímenes de pensamiento coloniales, a la vez que salvaguardan la interrelación y permanencia de formas modernas de explotación y/o dominación (Maldonado-Torres 2007: 129-130).

12 Como discuten Patterson y Kelley (2000: 13) y Gilroy (2002:17), la dificultad de cuantificar y dimensionar el tráfico de esclavos con exactitud se debe también a la invisibilización de la influencia e importancia africana en la construcción de la sociedad capitalista moderna.
} 
desembarcó en Puerto Rico en 1519 (Eltis 2001: 17). ${ }^{13}$ No obstante, el tráfico había sido iniciado por Portugal ya en el siglo XV (Klein 2010: 9) y seguido luego por España y otros países europeos en ese mismo siglo. Los registros dan cuenta de viajes de navíos portugueses expresamente imbuidos en la tarea de aprisionar africanos para el trabajo esclavo ya en 1441 (Russell-Wood 1978:16). Entre esta fecha y 1519, no obstante, estos esclavos fueron destinados únicamente a puertos europeos y a los recién invadidos archipiélagos de Madeiras y Canarias, en el Atlántico europeo (Eltis 2001: 17).

Los portugueses ocuparon durante casi cuatro siglos un papel central en este tráfico y la progresión del número de africanos transportados por navíos de esta nacionalidad nos apunta a las dimensiones del crecimiento de este "mercado". ${ }^{14}$ En términos totales, aunque no se conoce el número exacto de africanos desplazados hacia las Américas, se calcula que la cifra varíe entre 10 y 20 millones de personas (entre el siglo XVI y el XIX), constituyendo uno de los tres movimientos poblacionales más expresivos de la era capitalista (Sutcliffe 1998: 57). Y consolidando, además, la "migración" forzosa más violenta y amplia de la historia de la humanidad hasta la fecha (Cáceres 2001: 10; Lovejoy 1992: 473). ${ }^{15}$ Asimismo, hay que considerar

\footnotetext{
${ }^{13}$ Esto no quita la posibilidad de que esclavos y descendientes de esclavos hayan sido traídos a las Américas desde el viaje de Colombo, trabajando en los navíos. En este caso, no se trata del tráfico específico de africanos a las colonias, sino una expresión de su uso en Europa. De ahí que el autor considere que el tráfico en sí mismo hacia el nuevo mundo haya sido iniciado con el primer navío destinado para este fin, en 1519 (Eltis, 2001:17).

${ }^{14}$ Entre 1450 y 1460 los navíos lusitanos transportaron 800 africanos por año; entre 1460 y 1480 , este número sube a 1500 esclavos, pasando a 2000 entre 1480 y 1500 y, finalmente, a la cantidad de 3000 africanos anuales en 1510 (Klein, 2010: 11).

15 Investigadores dedicados al estudio de los africanos y afro-descendientes en diferentes contextos de las Américas han generado una especie de consenso sobre cómo definir este desplazamiento humano, prefiriendo el término "diáspora", al término "migración”. Según Butler (2007), Gordon y Anderson (1999) y Yelvington (2001) el término "diáspora" se adecua mejor a la experiencia afro-descendiente por permitir entender la manera como los sujetos y grupos constituyen activamente su sentido de pertenencia e identidad. Según Butler (2007) el concepto diáspora haría referencia a que: "en primer lugar, el grupo de salida tiene dos o más destinos, creando, en lugar de la bipolaridad, la dispersión implícita en el término diáspora (...). En segundo lugar, hay que mantener alguna relación con la tierra de origen [homeland], no
}

que las embarcaciones que transportaban a estos africanos presentaban condiciones severamente precarias. Lovejoy (1982: 481-491) calcula que entre un 15\% y $25 \%$ de los sujetos no llegaban con vida a su destino. Dadas estas circunstancias, es posible suponer que la cantidad de personas efectivamente retiradas del continente sea bastante superior al número de africanos que aportaron con vida al nuevo mundo.

Otro dato relevante, al que podemos acompañar observando las transformaciones que la industria portuguesa del tráfico sufrió, se refiere a los sitios de origen de los africanos esclavizados, y también a los principales puertos de partida en el continente. Como cita Klein (2010: 10-12), entre 1440 y 1512 , los portugueses realizaron incursiones africanas en las regiones de Mauritania, Senegambia y en la Costa del Oro. A través de estas incursiones aprisionaron africanos de los actuales territorios de Senegal, Gambia, Cabo Verde y del Golfo de Guinea. A partir de 1512, los portugueses logran asociarse al rey del Congo, con lo que el aprisionamiento de esclavos se expande por toda la costa occidental africana. A partir de 1576, con la invasión del reino de Luanda, los portugueses fundan allí lo que sería, hasta el siglo XIX, uno de los principales puertos de "exportación" de esclavos en África, incursionando continente adentro en esta latitud. ${ }^{16}$

Más allá de la importante participación de los portugueses, la esclavitud negra fue una parte sustancial de los emprendimientos económicos también de ingleses: siete de cada diez navíos transportando esclavos portaban banderas de estas dos nacionalidades (Eltis 2001: 20). Pero franceses, holandeses y españoles también participaron activamente en el "negocio". Los

\footnotetext{
importando si esta continúa o no existiendo después de la dispersión diaspórica. En tercer lugar, debe haber una identidad común entre los del grupo diaspórico. Finalmente, la diáspora tiene que persistir por dos o más generaciones" (Butler 2007:126. Traducción de las autoras).

${ }^{16}$ Cáceres (2001:10) sintetiza los principales sitios de origen de los africanos esclavizados en las Américas confirmando que ellos provenían de las siguientes regiones principales: la Costa del Oro (saliendo de los puertos de Cabo Coast Castle y Anomabu), de la Bahía de Benín (saliendo del puerto de Whydah, hoy día conocido como Dahomey), la bahía de Biafra (de los puertos Bonny y Calabar), y de África centro-occidental (de los puertos de Cabinda, Benguela y Luanda).
} 
portugueses habrían controlado el tráfico hasta 1640 y después de 1807. Los británicos habrían asumido el control en los momentos intermedios a estas dos fechas (Eltis 2001: 20). Según Eltis, "los traficantes franceses, holandeses, españoles, daneses y estadounidenses aparecen como pequeños jugadores en comparación [con británicos y portugueses] pese a que en algunos momentos específicos, estos países asumieron importancia en el tráfico" (traducción propia). Es en el marco de la importancia macro-económica representada por el tráfico de africanos para las colonias, y de su fundamental articulación con los procesos de acumulación de las más ricas naciones europeas del período moderno, que podemos explicar por qué desde inicios del siglo XVI y hasta fines del siglo XIX, el flujo esclavista hacia las Américas -del norte, centro, sur y el Caribe- no se ha detenido. El proceso se finaliza, al menos formalmente, en 1888 cuando Brasil declara ilegal el uso de mano de obra esclava africana. ${ }^{17}$

En relación al tráfico de esclavos africanos y su uso en las colonias españolas, hay algunas salvedades que subrayar. En lo que concierne a los doscientos primeros años de la explotación de la esclavitud negra (siglos XV y XVI), España prefirió entregar a terceros el tráfico, concediendo "derechos de explotación" de la venta de africanos a las Américas, denominados asientos (Eltis 2000: 23). Esto incidió en que gran parte del tráfico hacia la América hispánica estuviera a cargo de navíos de otras nacionalidades, especialmente portugueses. A partir del siglo XVI, no obstante, esta realidad cambió con el protagonismo de los británicos entre aquellos que más transportaban negros a las colonias españolas. Este predominio se hace notar especialmente entre los siglos XVI y XVIII, tras los tratados de paz firmados entre Inglaterra y España en Utrech (Tratado de Asiento). A partir de este acuerdo, Inglaterra gana el "derecho" de explotar el tráfico de negros entre África y las colonias españolas de las Indias Occidentales, entregando a éstas un total de 4800 negros por año (Marx 1996: 377).

\footnotetext{
${ }^{17}$ Cuba y Brasil fueron los dos últimos países del globo en "erradicar", por lo menos jurídicamente, el esclavismo africano: Cuba en 1886 y Brasil en 1888 (Levine 1989: 202). Se sabe, además, que Brasil fue el país receptor prioritario de africanos: aproximadamente 4 millones desembarcaron en el país entre los siglos XVI y XIX (Eltis 2001: 44).
}

El tratado permitió que los ingleses incrementasen paralelamente el contrabando de africanos, de manera que se supone que esta cuota de esclavos significase muy poco del total de seres vivos llevados por naves británicas a la América hispánica (Marx 1996: 378)..$^{18}$ A fines del siglo XVIII, tras asumir el control de la Bahía de Biafra en Áfri$\mathrm{ca}$, los españoles reasumen cierta potestad sobre el tráfico de esclavos a sus colonias, pasando a exportar sistemáticamente a Cuba, última de sus colonias en independizarse, y última de las colonias hispánicas en erradicar la esclavitud (Eltis 2001: 23). Así, el tráfico de africanos a las colonias controladas por España ha sido predominantemente llevado a cabo por portugueses y británicos.

Entre las rutas desarrolladas por los portugueses hacia la América hispánica, fueron fundamentales aquellas que tenían como puerto inicial americano a las ciudades de Río de Janeiro y Salvador de Bahía. Entre las principales rutas de distribución de los esclavos africanos a la América española, se destaca aquella que, controlada por lusitanos, aportaba a Salvador de Bahía, siguiendo luego a Buenos Aires, Tucumán y Lima (Cáceres 2001: 10). Es relevante también la ruta que llegaba al continente por América Central, llegando a territorios andinos a través de la entrada al Virreinato Peruano por el puerto de Trujillo, desde donde los esclavos eran distribuidos a otras localidades del mundo colonial español.

Los sitios prioritarios de destino de los africanos en las colonias hispánicas se situaban en el Caribe y Centro América. En las colonias sudamericanas se utilizaba mayormente la mano de obra indígena local, aunque también se destinaron esclavos africanos prioritariamente a localidades que hoy pertenecen a Venezuela, Ecuador, Colombia y Perú. En este sentido, en lo que a la América hispánica se refiere, se podría decir que entre los grandes puertos de recepción del tráfico de esclavos que se conocen, se cuentan: Cartagena (Colombia), Portobelo (Panamá), la Guaira y Cumaná (Venezuela), Buenos Aires (Argentina), Lima y Callao (Perú) (Whitten y Friedemann 1974).

\footnotetext{
${ }^{18}$ Así, de acuerdo con Marx (1996), la predominancia de los británicos como contrabandistas de africanos al Nuevo Mundo no es una casualidad: es parte sine qua non del proceso de acumulación que ha permitido a Inglaterra consolidar su dominio económico, años más tarde, en su revolución industrial.
} 
Como mencionamos anteriormente, el mantenimiento de este tráfico africano se relaciona fundamentalmente con la rentabilidad que la esclavitud proporcionaba en suelos coloniales. ${ }^{19}$ Esto, en parte, influyó de manera determinante a que, en términos historiográficos, los primeros trabajos que dan cuenta de la presencia negra en la América hispánica estuvieran asociados a los problemas y beneficios coloniales que trajo consigo esta trata negrera. De ahí se desprende el importante desarrollo del tema desde una perspectiva de la circulación, el comercio y el tráfico (Cortés 1963; Whitten y Friedemann 1974). Luego, la población afro fue transitando entre la esclavitud como institución jurídicamente aceptada y legitimada por grupos dominantes, y las sumisiones o escapes asociados al contingente negro en aquella época (San Martín 2007: 197). Simultáneamente, los africanos y sus descendientes fueron mezclándose con la población autóctona y con los europeos residentes en estas tierras, en un proceso que les ha "integrado" a las estructuras raciales y de desigualdades latinoamericanas. En el apartado que sigue, nos dedicaremos a transitar desde esta configuración más amplia, a una configuración local particular. Nos dedicaremos a especificar este proceso de "incorporación" de africanos a la ciudad de Arica.

\section{* Configuraciones de la presencia africana en Arica: el Virreinato Peruano hasta la República Chilena}

Antes de abordar específicamente la presencia africana en Arica, conviene dedicar unas cuantas líneas a la ubicación de la ciudad en la actual división territorial del Estado chileno. Localizada en el área conocida como Norte Grande, Arica es el asentamiento urbano más septentrional del país. El Norte Grande engloba a un territorio desértico, perteneciente al ecosistema del Atacama, y que está constituido por tres regiones de la actual división político-administrativa chilena. La primera de ellas es la región de Arica y Parinacota (capital en Arica), que colin-

\footnotetext{
${ }^{19}$ Sobre esta rentabilidad, basta con afirmar que, durante la primera mitad del siglo XVIII en Brasil, el coste de adquisición de un esclavo se amortizaba con un período de entre trece y dieciséis meses de trabajo del mismo. Incluso en los momentos de encarecimiento del valor del africano en el mercado brasileño, como en inicios de 1700, la amortización ocurría en un intervalo máximo de treinta meses (Fausto 1995: 27).
}

da con Perú. Al sur está la región de Tarapacá (con capital en Iquique) y, al sur de ésta, la región de Antofagasta (con capital en Antofagasta). Las tres capitales regionales se sitúan en la costa pacífica, constituyéndose, históricamente, como puertos.

El territorio del Norte Grande fue anexado a la geografía nacional chilena después del conflicto con los vecinos Perú y Bolivia a fines del siglo XIX, al que se conoce como la Guerra del Pacífico o del Salitre (1879-1883). Este enfrentamiento militar ocupó un papel central, tanto en lo que concierne a la configuración territorial de las tres naciones, como en lo que se refiere a la constitución del mismo principio de nación por parte del Estado chileno. La creación de la frontera norte de Chile después de la guerra impactó fundamentalmente la ciudad de Arica, que fue disputada por este país y por el Perú hasta la tercera década del siglo XX. Tras el conflicto, el territorio al sur del antiguo departamento peruano de Tacna, al que pertenecían las ciudades "siamesas" Tacna y Arica (González 2008: 13), estuvo ocupado por el ejército chileno y constituyó una zona en litigio. El litigio fue "solucionado" en junio 1929 (González 2008: 14): Tacna pasó definitivamente a Perú y Arica a Chile (Podestá 2011: 124). Esta división rompió parte de la dinámica económica, social y política entre las dos ciudades, impactando la complementariedad económica de Arica como el histórico puerto de la capital departamental, Tacna.

Así, podemos afirmar que Arica, durante siglos, se ha visto marcada por las múltiples tensiones y adscripciones socio-políticas, por flujos migratorios en diversos sentidos (y motivados por factores que van desde las prácticas culturales históricas en la zona, hasta la invasión y persecución militar). La ciudad se ha identificado primero como parte del Virreinato del Perú hasta el año 1821 en el período Colonial, luego como parte del Estado nacional peruano (desde 1821 hasta 1883). Como explicitamos anteriormente, constituyó zona de litigio entre Chile y Perú (entre 1883 y 1929), para finalmente adscribirse al Estado nacional chileno desde 1929 (Díaz 2010: 160). En este sentido, para entender el proceso histórico de la presencia africana y afrodescendiente en Arica, tenemos que remitirnos al pasado colonial de la ciudad, en el marco del Virreinato del Perú, y luego a su participación en la república peruana. Solamente así podemos situar su 
importancia como puerto receptor de esclavos africanos en el territorio desértico de la costa pacífica.

El Virreinato del Perú constituyó uno de los principales ejes económicos de la colonización de la América hispánica. A través de los puertos peruanos los africanos fueron introducidos al mundo andino. El uso inicial de su mano de obra para la extracción de metales preciosos en el actual territorio del Perú fue lo que estableció la condición económica primordial que motivó su introducción en el litoral del Pacífico. No obstante, tras los primeros años, los africanos pasaron a ser utilizados en todo tipo de trabajo, desde las más diversas faenas agrícolas, pasando por la cría de ganado, hasta los trabajos domésticos y urbanos.

Según Cairati (2011: 122), "no se puede establecer con certidumbre la procedencia geográfica de los africanos que llegaron al Virreinato del Perú". Pero los que llegaron es posible que hayan transitado a través de dos rutas. La primera era el camino costero hacia el norte de Lima, lo que involucraba el circuito Lima - Tumbes, pasando por todos los valles de la costa norte del Perú. La segunda ruta transitaba por el camino costero hacia el sur, navegando entre Lima - Chincha (Puerto de Tambo de Mora), Pisco - Ica, Nazca - Arequipa Arica. Es probable que los primeros esclavos que entraron al litoral del Pacífico fueran traídos directamente de África Occidental (Whitten y Friedemann 1974), posiblemente de Mauritania, Senegambia y en la Costa del Oro (Klein 2010: 10-11). De ahí también procedían los esclavos que venían de la península Ibérica, que ya estaban "hispanizados" (cristianizados y hablando lenguas románicas) y que fueron los primeros en llegar a América (Klein 2010: 10). ${ }^{20}$ No obstante, a partir del siglo XVII con el control asumido por los portugueses en la costa del Congo, en Luanda y en demás regiones del occidente africano, se conoce que llegaron esclavos

\footnotetext{
${ }^{20}$ A partir de 1530 los esclavos pasan a ser mandados directamente de África a las Américas, a través del puerto africano de San Tomé. Esto eliminaba el período de estadía de los esclavos en la península Ibérica, y marca un fuerte cambio en la "industria esclavista”, en la medida en que ésta se reviste de otros sistemas de dominio por medio de la fuerza. Este cambio, a su vez, redujo los costes de la "exportación" de esclavos al nuevo mundo, potenciando los lucros de la empresa esclavista portuguesa y española (Klein 2010: 11).
}

africanos al Virreinato del Perú desde diversos orígenes. Según Lucía Charún-Illescas, las etnias ${ }^{21}$ que encontraron y que se mezclaron en el Perú eran los:

"Carabalí, procedentes de la región del Calabar, al suroeste de Nigeria, Lucumí, de etnia Yoruba, Mandinga, procedentes de la zona entre Senegal y el Golfo de Benín, Mina, hombres de la región cerca de la Costa de Oro y el área conocida como Costa de los esclavos, Congos y Mondongos, etnias de Congo" (CharúnIllescas 2001: 15).

La mano de obra esclava desde su entrada al Perú, fue distribuida en diferentes puntos del territorio:

"Después de la venta, los esclavos eran trasplantados en diferentes zonas costeras, donde se produjeron fenómenos de mestizaje biológico, social y cultural de los que proceden las actuales comunidades afro-descendientes, en las regiones de Piura, Lambayeque, Lima, Chincha, Pisco, Ica y Tacna" (Cairati 2011: 123).

Obsérvese que en este segundo relato se menciona a Tacna como centro receptor, pero no se cita a Arica, pese a que esta segunda ciudad fuera el principal y más cercano puerto de la capital provincial. Aún así, el texto nos permite establecer dos informaciones centrales. La primera de ellas guarda relación con el hecho de que la incorporación dinámica y multifacética del africano a la sociedad colonial peruana, ya profundamente pluriétnica desde su constitución inicial, fue entonces un hecho incuestionable. ${ }^{22}$

\footnotetext{
${ }^{21}$ Como discute Líbano-Soares (2002), la definición de las etnias de origen son parte del mismo proceso colonial de etnificación de los negros. En un número significativo de casos los africanos recibían como "origen" en los registros el nombre del puerto/ciudad de donde habían partido en África. Estas clasificaciones étnicas son fruto de la misma "industria del tráfico".

${ }^{22}$ Cabría matizar, no obstante, la magnitud de la esclavitud negra en el Perú, observando que ahí se contó menos con la fuerza de trabajo africana que otros países latinoamericanos. Pues, “...a diferencia de Haití, el Perú no era una sociedad esclavista. La proporción de esclavos era muy inferior a la de sociedades como Haití, Cuba o Brasil, y el aporte económico de la esclavitud, si bien era importante, no representaba un interés vital para la economía peruana. De todas maneras, la esclavitud en el Perú representaba una fuente importante de ingresos y prestigio social (no sólo para las clases dominantes) y un mecanismo de control social altamente valorado por las elites, de manera que cualquier proyecto para liquidarla era visto necesariamente como un ataque a la propiedad y el orden social. Aunque hubo posturas contrarias a la esclavitud
} 
Por otro lado, la segunda de las informaciones que podemos destacar, se refiere a que Arica era parte de este contexto de recepción de africanos en el Virreinato del Perú, conectada como estaba a las rutas de distribución de esclavos en la costa pacífica, estando funcionalmente ligada a centros importantes en aquel entonces, como Arequipa y Tacna. En este sentido, el puerto de Arica estuvo asociado a la trata de esclavos, y luego la zona urbana y rural de la ciudad jugaron un papel fundamental en cuanto a la entrada y asentamiento de las colectividades de africanos que han llegado al puerto ariqueño.

Coherentes con el propósito de visibilizar la importancia de la presencia afrodescendiente en este contexto ariqueño (tanto en la composición de las realidades coloniales, como en las nacionales), cabría preguntarse qué rol social ha jugado la presencia negra en Arica en lo que se refiere a los procesos de formación de la sociedad civil local en la Colonia y después de ella, en el marco del Estado peruano y también del Estado chileno. En este sentido, es posible dar seguimiento a registros documentales ${ }^{23} \mathrm{e}$ investigaciones regionales que se han llevado a cabo sobre la presencia africana en Arica, mayoritariamente, desde perspectivas jurídicas (Rivera y Rubio 2012), históricas (Briones 1991), turísticas, (Narváez 2008), patrimoniales (Araya 1999), y arqueológicas (Galecio 2011).

Estas investigaciones y documentos han vinculado los africanos en Arica a la minería, a la agricultura, a las labores manuales y a los servicios domésticos, entre otras ocupaciones urbanas (Briones 1991: 12). Algunos autores que han trabajado con los censos expuestos por Wormald, ${ }^{24}$ como es el caso del de 1871, han fundamen-

(generalmente en la forma de sugerencias en favor de una abolición gradual), no existió en el Perú un movimiento abolicionista sostenido, y mucho menos propuestas que pusieran a los propios esclavos en capacidad de decidir su futuro" (Aguirre 2005: 18-19).

${ }^{23}$ Las principales fuentes de información sobre la presencia de africanos en Arica estaría recopilada en los Archivos Documentales Vicente Dagnino, Universidad de Tarapacá, Arica. Informaciones muy relevantes pueden encontrarse también en el Archivo Regional de Tacna, en el Archivo Histórico de Lima, específicamente en sus fondos Coloniales y Republicanos y en el Archivo Nacional Histórico de la ciudad de Santiago de Chile.

${ }^{24}$ Alfredo Wormald Cruz fue un eminente historiador ariqueño que investigó y publicó trabajos sobre la historia regional de Arica. Entre ellos, algunos asociados a los censos de población de 1871 y 1876 de la ciudad. tado el criterio de que existió una cantidad considerable de población negra en Arica, basándose en la afirmación de que entre negros y mestizos de negros constituían el 58\% de la población local (Wormald 1966 [1903]: 161). Briones (1991 y 2004) afirma que el sur peruano y el norte chileno habrían concentrado una parte importante de la población africana y afrodescendiente que aportó a la costa pacífica, y que "dentro de este territorio destaca Arica que, por presentar condiciones climáticas especiales, fue una zona favorable para el asentamiento de población negra" (Briones 1991: 15). ${ }^{25}$ Aún sobre la numerosa presencia en Arica, comenta Artal (2011):

"La población negra en Arica siempre fue numerosa. El año 1555 Carlos V acordó al ex gobernador del Perú, licenciado Cristóbal Vaca de Castro, en reconocimiento a los valiosos servicios prestados a la Corona, la internación en ese país de 500 piezas de ébano libres de derechos. Tal merced constituyó un espléndido regalo, pues en esos años el impuesto de entrada por cada negro ascendía a 80 ducados, más el $6 \%$ sobre 160 pesos, valor en que, según parece, se estimaba el costo de la pieza. Pues bien, cuando se concedió dicho premio a Vaca de Castro, ya había en Perú más de 1.200 negros distribuidos en varios sitios de la costa. Y uno de esos sitios era Arica" (Artal 2011: 3).

Según Briones (1991), existió entre los años 1690 y 1740 un comercio dedicado exclusivamente a la compraventa de negros en la ciudad, el cual se habría ubicado en el Valle de Lluta (en una de las salidas de la ciudad, en dirección al interior altiplánico). Este comercio habría estado a cargo de Francisco Yáñez, Ambrosio Sánchez, Pedro Sabarburu y Luis Carrasco, propietarios de los llamados "Criaderos de Negros". Estos "criaderos" consistían en negocios en los cuales se compraban mujeres y hombres negros a los que mantenían en cuarentena y encerraban en establos para que se reprodujeran. Luego el dueño de las "piezas", bautizaba a todas las criaturas nacidas con su apellido, inscribiéndolas con el nombre de su madre y agregando que eran hijos de "padre desconocido". Los dueños

\footnotetext{
${ }^{25}$ Consideramos que las explicaciones de Briones acerca de las condiciones climáticas no son suficientes para asumirlas como razones determinantes del asentamiento durante siglos de poblaciones africanas y de su descendencia en Arica. Valdría la pena rescatar la asunción de que existen factores económicos, políticos y sociales por detrás de la permanencia de africanos en la ciudad, y que esto nos permita relativizar el determinismo ambiental como factor explicativo.
} 
y amos de estas "piezas" llegaban a realizar más de seis bautizos simultáneos y entre los niños no había más que algunos meses de diferencia (Wormald 1966 [1903]: 159).

Pero la existencia y persistencia de estos "criaderos" son objeto de debate entre estudiosos del tema. Entre algunos historiadores santiaguinos e investigadores del norte de Chile hay una aparente falta de consenso sobre su presencia en territorio ariqueño. La postura santiaguina es la de cuestionar la veracidad de la existencia de los "Criaderos de Negros" y del mercado de esclavos de Arica. Indagan también sobre la importancia numérica de esta presencia africana, en parte cuestionando los números censales presentados en el período en que Arica integraba la república peruana. Consideramos oportuno hacer referencia a que no hemos encontrado información en la literatura consultada que apoye la postura santiaguina. Por otro lado, sí pudimos consignar que existen antecedentes de investigaciones arqueológicas en suelo ariqueño de elaboración de dos expedientes técnicos para la declaración de Monumentos Históricos, entre los que se encuentra el Informe "Casa Criadero de Esclavos" en el sector de Molle Pampa, Valle de Lluta (Galecio 2011).

Más allá de la existencia de los "criaderos", lo que sí podemos observar es que la explotación de africanos en Arica siguió su rumbo hasta 1854, cuando se elimina formalmente la esclavitud negra en el Perú (Aguirre 2005: 18; Cairati 2011: 126). Pero ya antes de la abolición "una parte de los negros esclavos del Virreinato en Arica fueron comprando su libertad" (Briones 1991: 8). Briones no específica la manera en que esto ocurría, pero gracias a disposiciones legales asociadas al movimiento de independencia de las repúblicas latinoamericanas (poco después de 1821), se emitió desde Lima la ley de "libertad de vientres" para todo el Perú (Cairati 2011: 126). La ley constituyó una de las razones concretas que legitimó el nacimiento de afrodescendientes no esclavizados, que pasaron a desarrollarse como "trabajadores libres" en diversas ocupaciones en el ambiente rural y urbano. Tras la abolición de la esclavitud, los africanos transitaron por el período republicano peruano desempeñándose como pequeños propietarios de negocios, trabajadores asalariados y productores agrícolas.

Lo que también habría que subrayar es que, en territorio ariqueño, la población afrodescendiente -antes y después de la abolición de la esclavitud- configuró un hábitat propio. Ejemplo de ello es el barrio negro conocido como Lumbanga y los valles productivos de Lluta y Azapa, permaneciendo en estos espacios desde 1854 y hasta el estallar del conflicto armado con Chile y Bolivia. Este segmento de la sociedad civil ariqueña fue impactado de manera sensible por los cambios sociopolíticos más contundentes que sacudieron a esta zona en su incorporación al territorio chileno y su transformación en territorio fronterizo, ambos procesos asociados a la Guerra del Pacífico.

Así, los afroariqueños también lidiaron con las negociaciones entre el Estado chileno y el peruano posteriores al conflicto y fueron unos de los protagonistas de las masivas migraciones de ciudadanos peruanos hacia el sur de Perú, como resultado de la victoria de Chile. El predominio chileno da inicio, simultáneamente, a la oficialización del proceso de chilenización y blanqueamiento racial que tuvo lugar en el territorio (Urquhart 2008: 28). La guerra tiene, en este contexto, un papel fundamental a la hora de redimensionar las construcciones identitarias que impactarían sobremanera a negros e indígenas en el Norte Grande. Sobre este particular, Díaz expresa:

"Arica posee una profundidad histórica que se amplifica en su perspectiva temporal, mucho más allá de los episodios bélicos vinculados a la Guerra del Pacífico y la correspondiente anexión del territorio y sus gentes a la soberanía chilena. Lo que gravita la debida reformulación de interrogantes que permitan problematizar una sociedad local que posee una diversidad de historias, que se hunden en la ciudadanía peruana como entre las poblaciones indígenas andinas, en los afro-descendientes o en los migrantes extranjeros, siendo un crisol donde confluyen identidades culturales diversas" (Díaz 2010: 182).

Luego del Tratado de Ancón (1883) entre Chile y Perú, que determinó el final de la guerra, se hicieron una serie de pactos asociados a la administración de Tacna y Arica, que durante años quedó a cargo de Chile. Poco a poco, muchos de esos acuerdos fueron perdiendo validez debido a los dilatados desencuentros entre las partes. Dando paso a años en los que el poder burocrático y político chileno pudo operar en pro de un proceso de chilenización o de imposición de la "chilenidad" en estos territorios, encargándose de manera particular, de "concientizar" y nacionalizar a la población local de 
Arica. Primero con fines electorales y luego para validar el poder estatal chileno de manera permanente en el territorio. Dicho proceso operó a través de diversas perspectivas que se resumen en la exaltación de los símbolos patrios, la aplicación de un ordenamiento jurídico, la instauración de su aparataje burocrático y militar, y el sistema escolar. Curas párrocos o empleados civiles, operaron (al parecer) bajo la lógica de "integrar a todos", y mediante cualquier método, a la comunidad imaginada chilena.

Los resultados de esto se pueden observar en el peso nacionalista que se manifiesta e impone y que todos comprenden y aceptan como parte de la sociedad fronteriza, a pesar de los múltiples enfrentamientos que originó entre bandos peruanos y pro chilenos, así como en las fuertes oleadas migratorias hacia Perú por estos años (Araya 2010: 14-15). Este proceso inaugura históricamente un nuevo período de invisibilidad para los afrodescendientes en Arica, en la medida en que la integración nacional de la ciudad a Chile fue asumida como necesariamente conectada a la chilenización de las gentes que allí vivían y de su adhesión prioritaria al reconocimiento identitario chileno, antes que étnico (ya fuera esta etnicidad africana o indígena). Aquí también vemos entrecruzarse claramente los dos principios de control y jerarquía: por un lado, la lógica colonial de dominio del otro conquistado; y por otro la lógica de la construcción de la mitología de unidad nacional.

Con base en los planteamientos anteriores, podemos observar que la presencia afroariqueña y su papel en lo que Díaz (2010: 182) denomina la "confluencia de identidades diversas" en Arica, se constituye como un elemento fundamental para comprender la manera como, en la localidad, han coincidido una lógica colonial de jerarquía racial y una lógica nacionalista de invisibilización de la diversidad sociocultural. Esto suscita, a su vez, cuestionar y redimensionar el significado que tiene el actual movimiento por el reconocimiento en Chile de una etnicidad afroariqueña. Habría que comprender su desarrollo histórico como un conflicto entre jerarquías sociales, económicas y raciales y formas modernas a partir de las cuales las fronteras nacionales fueron redibujadas en la triple frontera andina. En gran medida, se puede decir que esta perspectiva asimilacionista que ha jugado el Estado chileno en el Norte Grande desde la Guerra del Pacífico man- tendrá unos mismos lineamientos políticos hasta fines del siglo XX, con la vuelta del país a la democracia, tras el régimen dictatorial de Augusto Pinochet.

\section{* Configuraciones del reconocimiento} ÉTNICO EN EL ESTADO CHILENO POSTDICTADURA

La transición del período dictatorial hacia la democracia en Chile ha marcado la pauta de una nueva política de "integración" de la diversidad étnica. Se observa así un giro desde la mirada históricamente asimilacionista con que el Estado chileno planteó la presencia (e invisibilización) de sus comunidades indígenas, hacia un posicionamiento que define, aunque con ciertas incoherencias argumentativas, un multiculturalismo constitutivo de los contenidos identitarios de la nación (Boccara y Bolados 2010: 652). Este giro en cómo el Estado chileno plantea el paradigma étnico nacional (Segato 2007) incide en las políticas públicas que, desde fines de la década de 1980, marcan la pauta de los gobiernos postdictadura (Boccara y Bolados 2010: 653).

Hablamos de "incoherencias argumentativas" de esta asunción multicultural de la identidad nacional en Chile refiriéndonos a que el proceso, en gran medida, ha desplazado al debate desde un eje que lo posiciona como una cuestión de derechos y de justicia social, hacia una retórica que reifica la diferencia y diversidad como elementos de orden cultural. Pero con una lectura de lo cultural apremiada por cierto esencialismo, constituyendo lo político como supuestamente ajeno a esta construcción:

"Definiendo en una sola palabra de aparente sencillez este nuevo marco socio-ideológico y jurídico-institucional, el multiculturalismo se ha instalado con fuerza en la arena pública. Los problemas sociales se declinan desde ahora en clave étnica. La cultura ha llegado a ser una categoría central del discurso público y determinante en la construcción de las identidades sociales y políticas. Nuevos rituales públicos y un nuevo régimen visual contribuyen a fabricar la imagen de un Chile plural pero unido" (Boccara y Bolados 2010: 652).

Este reconocimiento de unas identidades étnicas como formas "de la cultura en su diversidad" implica y condiciona una lectura esencialista en cuanto tensiona los grupos sociales a presentar su supuesta diferencia como una 
que puede identificarse a través de rasgos culturales estaques. Como una diferencia observable en las formas de vestir, hablar, vivir, cultivar, en prácticas sociales, económicas y en rituales (religiosos o no). ${ }^{26}$ Simultáneamente, este proceso provoca que toda lucha por derechos por parte de los grupos indígenas sea entendida como "una lucha de minorías étnicas", desviación peligrosa sobre la que muchos autores han alertado, visibilizando los desenlaces de la acción política de las comunidades, especialmente las mapuche, en Chile (Román 2010: 31; Vergara y Foerster 2002: 36).

Este proceso de reconocimiento, en partes, corresponde a una respuesta del Estado chileno a un debate que, en los años 90, atingió la esfera global. La asunción de la inexorabilidad de la aceleración de los flujos -de gentes, mercancías, conocimientos, formas de ser y de estaren el mundo, suscitó la discusión sobre la necesidad de redimensionar la relación de los Estados democráticos modernos con la diversidad. Lo que se refiere no solamente a la ruptura de ciertas imágenes modernas de la homogeneidad, sino que también se refiere a la creciente capitalización de la diversidad cultural y étnica como objeto de consumo y de circulación global (Comaroff y Comaroff 2011).

Este debate dio paso a tres posturas políticas centrales. La primera de ellas, es aquella que aboga por la necesidad de reformular los derechos de ciudadanía, ahora asumiéndolos como poliétnicos y universalizando la diferencia como principio axiomático constitutivo de los Estados (Kymlicka 1995: 180-181). En segundo lugar, emerge la postura que aboga por la creación, en el marco de los Estados-nacionales, de derechos exclusivos para las minorías, lo que permitiría generar -incluso con la mantención parcial del marco normativo moderno que proyecta los derechos de ciudadanía a partir de nociones de homogeneidad- la garantía del cumplimiento del de-

${ }^{26}$ Esta instrumentalización política del performance de lo cultural, y por ende de la identidad, aún potenciando la emergencia de cierta cohesión política por parte de grupos indígenas y afrodescendientes a los que el Estado hizo caso omiso por tanto tiempo, también conlleva ciertos riesgos en la medida en que reproduce principios modernos de identificación potencialmente violentos hacia la diversidad interna de los grupos. Para un debate sobre las potencialidades y límites de este uso instrumental de la cultura, véase Grimson (2011: 135-170). recho a la diferencia (Parekh 2000: 270-271). ${ }^{27} \mathrm{Y}$, finalmente, habría una tercera postura: aquella que niega la posibilidad de que las diferencias sean democráticamente incorporadas; lo que plantea la imposibilidad de una constitución del principio de derecho ciudadano que no tienda a, o que no se constituya a partir de, la homogeneidad como valor fundador. Esta postura encuentra su más claro argumento en la obra de Samuel Huntington (Grimson 2011: 75).

La postura chilena, en este marco de debates, tendió, desde la democratización del país, al reconocimiento del derecho a la diferencia como uno que se restringe a las minorías. Esto, claro está, desplazó el replanteamiento del debate sobre los límites y caducidad de la ideología de homogeneidad constitutiva que sedimenta la cohesión imaginada del paradigma de la identidad nacional chilena. Un debate que Chile viene postergando y evitando y que afecta no solamente los grupos étnicos internos, sino también la forma como el país recibe a los migrantes internacionales (Stefoni 2005: 265-266).

Esta incorporación de los derechos de las "minorías" a la diferencia se materializó a través dos mecanismos centrales: un cambio constitucional, por un lado, y un cambio en cómo se cuenta y caracteriza, en los censos nacionales, la población del país. Los dos mecanismos son representativos del lenguaje del Estado chileno, de una cierta centralidad puesta sobre la formalización legal y numérica de aquello que la nación reconoce.

El primero de los mecanismos, el legal, se refiere a la aprobación de la Ley 19.253, de 1993, a través de la cual el Estado reconoció la existencia del pluralismo cultural en territorio nacional (Boccara y Seguel-Boccara 2005), reconociendo los grupos étnicos internos como componentes de la nación. Esto, en parte, reincide en el compromiso asumido por Chile con la firma y ratificación de convenios y tratados internacionales que sientan las bases de la posibilidad de autorreconocimiento de los pueblos indígenas y de su derecho al respeto a la diferencia y especificidad cultural. ${ }^{28}$ Se puede decir que la ley ha

${ }^{27}$ Para un discurso de defensa de esta postura en Chile, véase por ejemplo Sierra (2003).

${ }^{28}$ Entre ellos, la Declaración de los Derechos Humanos (UDHR 1947/48), firmada y ratificada por Chile en 1948; y el Convenio 
potenciado la organización indígena, la lucha por la autodeterminación, a la vez que ha impulsado procesos de etnogénesis (Gundermann y Vergara 2009: 124), lo que ha significado un intento de responder a las ansiedades de "diferenciación cultural" que el mismo marco normativo plantea.

El segundo de los mecanismos, se refiere a la inclusión de la autoidentificación étnica como parte de los datos computados por el censo nacional, lo que ha representado un reconocimiento numérico y formal de la existencia de grupos indígenas en Chile. ${ }^{29} \mathrm{La}$ inclusión ocurrió ya en el censo llevado a cabo en 1992, pero reproduciendo problemas de orden conceptual no menores en relación a la posibilidad de adscripción de los sujetos entrevistados (Gundermann et al. 2005).

En relación a estas dos formalizaciones de la cuestión del derecho a minorías en Chile, quisiéramos subrayar que, pese a sus limitaciones operativas y conceptuales, ellas han logrado potenciar cierta cohesión política por parte de las comunidades indígenas. Pero, innegablemente, este proceso se ha desarrollado reproduciendo la invisibilidad de los otros grupos étnicos que pudieran postular a su reconocimiento como "colectivos culturales minoritarios". Nos referimos a que tanto en la ley de 1993, como en el mismo censo, no se ha planteado la cuestión afrodescendiente. Se ha reproducido así la invisibilidad que estos grupos han sufrido en el marco de la república chilena desde su fundación. ${ }^{30}$ Pero, más allá de estas

169 de la OIT, firmado y ratificado por Chile en 2008 , que regula el auto-reconocimiento de pueblos indígenas, garantizando derechos fundamentales a estos pueblos.

${ }^{29}$ La simbología de los números en los Estados-nacionales no es mero detalle. Las estrategias de numeración constituyen mecanismos centrales de conformación de los proyectos nacionales, ayudando a forjar "identidades comunitarias y nacionalistas que de hecho fueron instituidas por el colonialismo" (Appadurai 2004: 117). Numerar gentes y espacios es una una tecnología simbólica del poder usada en la conformación del Estado como una comunidad imaginada. Es indisociable de la manera como la nación proyecta sus dominios, sus pertenencias y sus "otros" (internos y externos).

30 "En Chile republicano se suprimieron de los censos y estadísticas oficiales preguntas que permitieran identificar a los grupos humanos que hoy se conocen como afro-descendientes y que durante la colonia se identificaron como negros y mulatos principalmente" (Corporación Participa 2012:30). limitaciones, y no sin cierta contradicción inherente, el proceso de promulgación de la ley y el reconocimiento de la etnicidad indígena en el censo nacional son los factores que mueven la organización política en las comunidades afrodescendientes de Arica. La posibilidad jurídica y formal de un reconocimiento como grupo minoritario actúa como catalizador político, ayudando a condensar alrededor de un discurso más o menos acotado la causa de los movimientos afroariqueños. Y es así que diversas asociaciones se forman en Arica, centralizando sus discursos en la demanda por la inclusión de la identidad afrochilena en la variable de etnicidad del censo nacional. En el apartado que sigue presentamos tres de estos movimientos.

\section{* Configuraciones de una demanda POLÍTICA: LOS AFRODESCENDIENTES EN ARICA}

En la actualidad existen en Arica una serie de organizaciones de afroariqueños, entre las cuales podemos contar la ONG Oro Negro (fundada en 2001), la organización Lumbanga (fundada en 2003) y la Agrupación de Mujeres Hijas de Azapa (Fundada en 2012). Estas organizaciones han ido forjando un discurso político y una serie de movilizaciones colectivas alrededor de la lucha por el reconocimiento como grupo étnico ante el Estado, contra la discriminación, y abogando por la inclusión de la variable afrodescendiente en el censo nacional.

Como nos ha comentado Marta Salgado, presidenta de Oro Negro, los movimientos vinculan muy claramente la necesidad del reconocimiento numérico censal de los afroariqueños a la formalización estatal del reconocimiento de su etnicidad. Y lo entienden como un paso previo a la materialización de nuevas estrategias de construcción de políticas públicas que permitan visualizar la presencia afro en Arica y en Chile:

"Estuvimos en la Intendencia protestando, tocando tambores, salimos a los barrios a llevar encuestas [para ser aplicadas a los afrodescendientes] hasta conseguir con el gobierno regional la aprobación de un proyecto de 166 millones de pesos, que no es menor, para hacer ese estudio ¿Por qué queríamos que lo hiciera el INE [Instituto Nacional de Estadísticas]? Porque técnicamente está refrendado su trabajo (...) iY con esos datos! Son los datos duros para poder construir las políticas públicas que nosotros queremos. Nosotros aspiramos con este estudio primero 
que todo obtener una oficina de gobierno aquí en Arica, que a lo mejor tenga dependencia de la Intendencia Regional, para poder empezar a trabajar programas que tengan que ver con salud, con estudios, implementar en los currículos escolares el tema de los afrodescendientes de Arica como una cátedra" (Entrevista a Marta Salgado. Arica, noviembre 2013).

La incidencia política que van alcanzando los movimientos y agrupaciones de afrodescendientes en Arica en torno a su especificidad étnico-cultural es un punto central en lo que se refiere a la actualización de ciertas demandas históricas, profundamente vinculadas a estructuras de larga duración, las jerarquías raciales del colonialismo en América Latina, así como los procesos de incorporación desigual de negros, indígenas y mestizos al proyecto nacional tras las guerras del siglo XIX. En el discurso de los participantes se aprecia muy claramente una tensión entre darle materialidad a una "cultura identitaria afro" -expresada a partir de los bailes, comidas, danzas- y la necesidad de superar esta dimensión de expresión cultural de la diferencia en pos de una construcción política de derechos. Simultáneamente, vemos, en el discurso de los participantes de estos movimientos, la explicación de cómo el reconocimiento hacia las etnias indígenas ha impactado las proyecciones de sus demandas:

"A corto plazo, [nuestro objetivo es] sensibilizar a la población sobre la cultura afroariqueña: sea danza, el tema culinario, costumbres, artesanía... todo lo que tiene que ver con sensibilizar. $Y$ al largo plazo ser reconocidos por el Estado chileno. Pero también que el Estado visualice que existe una población afrodescendiente en Chile. Así como ellos visualizan que existen los rapanuis, que existen los quechuas, que existen los diaguitas, que son poquitos que quedan. Nosotros le pedimos al Estado que así como reconoce a estos ciudadanos, también reconozca a los afrodescendientes que están en este país" (Entrevista a Laura Zegarra. Lumbanga. Arica, noviembre 2013).

Pero es justamente en el sentido de superar la estrategia de culturalización per se de la cuestión afro que se enuncia la centralidad de la estrategia de cuantificación de la población afrochilena en el censo. Acá, el reconocimiento numérico aparece como un puente que permite superar las proyecciones "de corto plazo" -de expresión pública de lo cultural-, hacia demandas por igualdad de derechos sociales:
"Creo que si bien se avanza en el tema cultural, nos hemos quedado un poco pegados en hacer sólo eso. Es importante mantener este tema cultural pero hay que avanzar también en qué estamos haciendo después de haber tenido una caracterización o estudio que hizo la Alianza Afrodescendiente y saber que tenemos afrodescendientes viviendo en situación de pobreza, sin agua por ejemplo. [...] Ése es importante porque ahí se hizo un estudio de todas las que se reconocen, por lo menos los miembros que se identifican como afrodescendientes, reconocer qué tipo de trabajo tenían... igual que el censo nacional, similar pero para personas afrodescendientes, los que nosotros sabíamos que eran afrodescendientes. Justamente cuando hablamos de políticas públicas no hemos desarrollado a lo mejor un trabajo que llegue hoy a ellos, más allá que el baile y la cultura" (Entrevista a Rodrigo Toledo. Oro Negro. Arica, noviembre 2013).

Sólo teniendo en cuenta estos objetivos -esta enunciación de la necesaria complementariedad entre la identidad como forma cultural y como proyecto político- por parte de las organizaciones afroariqueñas, podemos comprender sus demandas y su incidencia frente al Estado y a la lucha por la igualdad de derechos, visibilizando la participación de los grupos étnicos en Chile, rompiendo el mito de la "no presencia" de la comunidad afrodescendiente en el país. En este sentido, algunas de las actuaciones de las organizaciones afroariqueñas ilustran muy claramente la dimensión histórica y política de sus demandas, permitiéndonos entender que el diálogo que inician con el Estado tiene una dimensión de crítica a los paradigmas étnicos (Segato 1999 y 2007) incorporados por el discurso de la identidad nacional chilena.

Un ejemplo de este tipo de encuentro lo protagonizó Oro Negro, primera organización no gubernamental, sin fines de lucro, de afrodescendientes en Chile. Su primera aparición pública ocurrió el 2000, en la Conferencia Regional sobre Discriminación y Racismo realizada en el edificio Diego Portales, en Santiago. En esa ocasión, el presidente de la república de Chile negó categóricamente la existencia de afrodescendientes en el país. Acto seguido se presentaron delante de él los socios fundadores de Oro Negro, todos ellos autoidentificados como afroariqueños, escenificando en esa ocasión un fuerte enfrentamiento simbólico. Su presencia en el acto desafió al presidente a decirles, cara a cara, que no había afrodescendientes en el país. La sencillez de este acto de autopresentación conlleva a una postura 
política compleja, en la medida en que rompe tácitamente el juego de invisibilización que desde el Estado se reproduce, a la par que afecta de modo muy directo el mito de homogeneidad en que se basa el paradigma étnico chileno, y que sedimenta también el modo específico en que, desde el centro del país, se plantea la incorporación de Arica como zona fronteriza.

Este acto de presentación funcionó como un catalizador del movimiento encabezado por Oro Negro, sirviendo como punto de partida de la actuación del colectivo. Ya en abril de 2001 la organización fue oficialmente fundada, adquiriendo personalidad jurídica. Este momento marca el inicio del desarrollo de un discurso sobre el sentimiento de autoidentificación étnico, ahora expresado a modo de lucha por los derechos, trastocando el mismo concepto de una inclusión de los grupos "minoritarios" entendida como un mero reconocimiento a su derecho a la diferencia cultural:

"Los principales objetivos de esta organización son: 1- Lograr el reconocimiento político y social de los afro-descendientes de Chile. 2-Rescatar y difundir las raíces culturales de los afro-descendientes. 3- Luchar contra la xenofobia, el racismo y todas las formas de intolerancia. 4- Capacitar y facilitar la participación directa de los afro-descendientes en áreas como: Salud, Educación, Participación Ciudadana, Artes y Deportes. 5- Proteger a los afro-descendientes en materias sociales como: Salud, Educación, Alimentación, Vivienda, trabajo y Discriminación" (Del Canto 2003: 85).

En el ámbito regional chileno, han sido recibidos por autoridades locales, intendentes y gobernadores en la ciudad de Arica. Se realizaron reuniones con parlamentarios y con el Secretario Regional Ministerial del Ministerio de Planificación y Cooperación de Chile. Han trabajado además con la Organización Participa y se hicieron presentes en debates académicos, como es el caso del Congreso Nacional de Antropología (Arica, noviembre de 2013). En este último evento, acompañada de otras organizaciones afrodescendientes y del Colegio de Antropólogos, Oro Negro realizó un foro de debate sobre la realidad de los afro-descendientes en Chile. Aquí se constata cómo la enunciación política se va construyendo de manera transversal desde diferentes formas de discurso, legitimando a diferentes niveles la defensa de una etnicidad afroariqueña.
Lo que es interesante también, en términos de este proceso de emergencia de un sentimiento de lucha por una identidad étnica, se refiere al hecho de que este proceso se conforma como una doble conciencia política: interna y externa a la nación. En términos de potenciar la enunciación de la identidad afro como realidad política, los líderes de organizaciones afrochilenas son activos participantes en eventos de carácter internacional y en grupos de generación de pensamiento crítico respecto a las realidades de las comunidades afrodescendientes en el contexto sudamericano. Esto denota la construcción de una forma de enunciar la cuestión que recupera, construye (y en algunos casos re-inventa) un sentido de experiencia diaspórica compartida por afro-descendientes en diferentes partes del continente.

Aquí, la enunciación política se encuentra con dos sentidos de reflexión histórica: la que se refiere al caso específico de los africanos en Arica y en Chile, y la que reinterpreta esta realidad en un marco histórico más amplio. Simultáneamente, se recupera el imperativo de un proyecto de enunciación que haga factible la existencia de una identidad afrochilena para nuevas generaciones. Opera un principio de etnicidad proyectado doblemente como un "pasado diaspórico" y como un "futuro de identidad":

"Nosotros somos una cultura viva y entonces necesitamos hoy día ese apoyo. Nosotros como Chile hemos empezado muy tarde este trabajo, pero sin embargo en 12 ó 13 años hemos avanzado mucho con respecto a otros compañeros a nivel internacional con los que trabajamos en Mundo Afro, de Uruguay, con Sergio Eco, de Honduras... tenemos relacionamiento con Paraguay, estamos trabajando con una ONG de Chile que es CEDEPU que tiene relacionamiento con África, Guinea Ecuatorial. Entonces hay mucho contacto, trabajamos con la Embajada de Marruecos, estamos haciendo muchas cosas, quizás a lo mejor nos falta cacarear más pero no es ésa la idea tampoco, sino ir lentamente construyendo un proyecto futuro de identidad para las personas, para las nuevas generaciones, porque yo les digo a los jóvenes: los viejos ya vivimos lo que teníamos que vivir, el proyecto es para las nuevas generaciones" (Entrevista a Marta Salgado. Arica, noviembre 2013).

Como nos hace ver el relato de Marta Salgado, Oro Negro se encuentra inserta en redes nacionales e internacionales, como es el caso de la Alianza Afrodescendiente, la 
Organización Participa (y su red Incide), el Grupo Barlovento. Este último es liderado por Sheila Walker, quien compiló la edición boliviana -con el apoyo del PIEB-31 del libro Conocimiento desde adentro, en que los afrosuramericanos relatan sus problemáticas. ${ }^{32}$ Paralelamente se establecieron contactos con los organizadores del Seminario Afroamérica, quienes firmaron una carta apoyando la inclusión de los afroariqueños en el Censo 2012, lo que finalmente no ocurrió.

Lumbanga es otra de las organizaciones de carácter cultural y social que ha logrado una dinamización comunitaria en torno a la causa afrodescendiente. En sintonía con lo que también postula Oro Negro, su objetivo fundamental es buscar el reconocimiento político, cultural y jurídico de los afrodescendientes en Chile y a nivel internacional. Una vez más, la inclusión de la variable afrodescendiente/negro en el censo chileno aparece como causa aglutinadora. Un segundo ámbito de cohesión política de la organización se refiere a la elaboración de una ley de reconocimiento de la etnia afrodescendiente en Chile.

Pero acá emerge también una interesante dimensión relacionada al reconocimiento de la "cultura" y del "patrimonio cultural" como bienes específicos a partir de los cuáles el grupo puede ganar reconocimiento frente al Estado, frente a las demás comunidades locales de Arica $y$, no menos, en la esfera global, en la medida en que este patrimonio puede servir de cabida al desarrollo de proyectos de turismo cultural internacional.

De esta manera, vienen enunciando su interés en el ámbito de lo patrimonial, por recuperar los valores asociados a la artesanía en totora, ${ }^{33}$ el patrimonio gastronómico afroariqueño y la celebración musical de festividades paganas y religiosas, destacando también la elaboración del recorrido turístico-educativo "La Ruta del Esclavo", que, curiosamente, es reconocida por el Estado, habiendo recibido el título de Ruta Patrimonial de Chile. El patrimonio cultural y la memoria pasan a integrar un pilar central del proceso de enunciación del reconocimiento étnico.

\footnotetext{
${ }^{31}$ Programa de Investigación Estratégica en Bolivia.

32 En este libro, Marta Salgado tuvo a su cargo la redacción del capítulo referente a Chile.

33 La totora (Typha angustifolia) es una planta acuática, un tipo de junco que puede alcanzar una altura de tres y hasta cuatro metros por encima del agua y que se utiliza para confeccionar artesanía.
}

Sobre la importancia de la memoria, Cristian Báez, uno de los líderes de Lumbanga, comenta:

"Había un tema de una africanización [en Arica] que no era pertinente a nosotros. Había todo un espectáculo de lo afro, de los afros, pero no había una investigación profunda de donde están los abuelos $y$ de los abuelos: había que investigarlos. O sea, había que entrevistarlos, estaban vivos. [...] Tenemos abuelos que están todavía, tenemos abuelos. [...] [Hay en Lumbanga] un sentido más ancestral de buscar a los abuelos y ahí buscamos a las familias emblemáticas: los Corbacho, los Baluarte, los Ríos... y los Bravo. [Familias que están] en Azapa algunos y acá también [en la ciudad]. Y los Quintana... La familia Quintana. Esas son las familias más antiguas. [...] que nosotros convocamos, que sabíamos que eran representativas [...] Entonces invitamos, y que participaron en Lumbanga" (Entrevista a Cristian Báez. Arica, noviembre 2013).

Esta misma postura aparece en obras publicadas por Báez en las que explicita este giro hacia la memoria, hacia las redes de parentesco y hacia "los abuelos" como eje constitutivo del sentido de etnicidad afro que, desde Lumbanga, se quiere impulsar:

"Reconstruir la memoria para una comunidad africana es la clave del desarrollo actual y su futuro, donde, de acuerdo a su historia, las comunidades pueden mirar el porvenir con mayor esperanza. A su vez, es posible argumentar la gran discriminación racial en la estructura social en este país desde que es república, lo que se evidencia en el ocultamiento e invisibilización del pueblo afrochileno" (Báez 2012: 15).

Dentro de los principales logros de Lumbanga, se encuentran la elaboración de un plan piloto en el que 480 familias de la Región de Arica y Parinacota fueron consultadas sobre su eventual pertenencia a la etnia afrodescendiente (realizado en octubre de 2009). También han articulado la instalación de una oficina municipal de desarrollo afrodescendiente en la comuna de Arica (julio de 2010). Y en relación al censo 2012 , articularon la posibilidad de que una vez finalizada la ejecución del mismo, el Instituto Nacional de Estadísticas (INE) realizara un estudio de caracterización de la etnia afrodescendiente de Arica (octubre de 2011).34

\footnotetext{
34 Dicho estudio se está concluyendo en estos momentos y la entrega de los resultados está previsto para diciembre de 2014.
} 
Un tercer colectivo es la Agrupación de Mujeres Hijas de Azapa, que surge en el año 2012 y que representa a las mujeres rurales afrodescendientes chilenas. Ellas se han organizado con la intención de incidir políticamente frente al poco interés a nivel estatal y de las organizaciones regionales, por brindar respuestas acertadas a los problemas relacionados con la vida rural de la comunidad de mujeres y hombres afrodescendientes. Alegan que las mujeres rurales afrodescendientes han establecido desde siempre una estrecha relación con la tierra, que les ha permitido sobrevivir y sostener a sus familias a lo largo del tiempo. Aquí, la enunciación de la identidad étnica está transversalmente construida por una dimensión de género, a la vez que asociada a unos principios de identificación con la labor rural que no son centrales para las organizaciones afrodescendientes radicadas en el contexto urbano ariqueño. En este sentido, el colectivo nos permite observar cómo la narración sobre las matrices identitarias del proceso étnico no es ni homogénea ni estática, sino que involucra diferentes maneras de entender la necesidad de reconocimiento frente al Estado chileno.

Las Mujeres Hijas de Azapa plantean la necesidad actual de incidir políticamente en cuanto a la implementación de políticas públicas: que éstas se encarguen de la protección de su territorio, considerándolo no solamente desde el punto de vista legal, sino también económico. Emerge el discurso de la vinculación entre el territorio y la subsistencia y reproducción del grupo étnico; lo que dirige el discurso directamente a un sentido de permanencia histórica en el espacio. De esta manera, la enunciación del reconocimiento identitario aparece de la mano de la promoción del rescate y protección de las "tradiciones", de la "flora y fauna" y de una centralización de la dimensión ancestral de sus tierras.

Las tres organizaciones que mencionamos tienen una importante capacidad de convocatoria, incidiendo en la reunión de figuras del mundo político regional en instituciones académicas como la Universidad de Tarapacá. Cada vez aparecen más producciones textuales creadas por afrodescendientes, lo que se inserta en un movimiento colectivo de visibilización del grupo. Simultáneamente, las redes tejidas a nivel nacional e internacional les permiten participar de iniciativas que incluyen la producción de textos por parte de investigadores afro- descendientes..$^{35}$ En ese sentido es oportuno mencionar, como ejemplo, el discurso enunciado por Patricia Castillo, directora del Sistema de Bibliotecas de la Universidad de Tarapacá (UTA-Arica), con motivo de la presentación del libro Afrochilenos. Una historia oculta, de Marta Salgado (2013), fundadora de la ONG Oro Negro. En la ocasión, Castillo refería que:

"Se trata de una temática urgente. Nuestra ascendencia es múltiple, sobre todo acá en la región. No me cabe duda que la multiculturalidad hace más rico a un espacio definido. La historia de los afro-descendientes la debe conocer la comunidad nacional, y qué mejor que partir por Arica" (www.uta.cl 2013).

\section{* Consideraciones finales: los movimientos AFROARIQUEÑOS EN SUS CUATRO CONFIGURACIONES}

El relato histórico construido subraya puntos esenciales para entender la realidad de la población afroariqueña en su lucha por su reconocimiento étnico ante el Estado chileno. Para ello se expusieron elementos que ayudan a visibilizar procesos silenciados sobre la presencia africana en Latinoamérica. Además de referirse al racismo con el que las comunidades diaspóricas afrodescendientes han tenido que lidiar, elementos que resultan comunes en la región.

Se abordaron a grandes rasgos las dimensiones y características del tráfico negrero hacia las Américas y la presencia africana en Arica desde la época virreinal peruana hasta la república chilena. Todo esto para cuestionar y redimensionar la génesis, las continuidades y rupturas que ha tenido el actual movimiento de reconocimiento y reivindicación étnica afroariqueña en Chile. En síntesis, hemos trabajado la construcción de una demanda de reconocimiento étnico por parte de la población afroariqueña a partir de cuatro configuraciones históricas,

\footnotetext{
35 Así empezaron a ganar reconocimiento en el contexto latinoamericano junto a otras organizaciones afrodescendientes. Ejemplo de esta puesta en papel de las concepciones políticas de los grupos es el libro Lumbanga: memorias orales de la cultura afrochilena (Báez 2012), y Oro Negro: una aproximación a la presencia de comunidades afro-descendientes en la ciudad de Arica y el Valle de Azapa (Del Canto 2003). Hay que mencionar además el libro Afrochilenos. Una historia oculta (Salgado 2013).
} 
todas ellas referentes a modos de operación de procesos de ocultamiento e invisibilidad de la contribución e importancia de la presencia afrodescendiente: una pertinente a su ocultamiento en la constitución de un sistema mundo moderno; otra vinculada a su marginalidad en el proceso colonial andino; una tercera referente a su silenciamiento en el proceso de transición de los territorios al sur de la república del Perú a la nación chilena, y un cuarto momento histórico, en el que esta invisibilidad es percibida por los propios agentes afrodescendientes, con la emergencia de una demanda política por el fin de la invisibilidad.

En el apartado "Configuraciones del reconocimiento étnico en el estado chileno postdictadura", discutimos cómo la posibilidad de que esta demanda sea enunciada se vincula no solamente a los procesos de conciencia política de las comunidades afroariqueñas, sino que se enmarca en un cambio de construcción del discurso político sobre la diversidad. Un cambio que impacta a Chile de forma puntual y específica en los años 90, en el marco de la democratización del país. En el contexto chileno, el reconocimiento de la diversidad constitutiva de lo nacional toma la forma jurídica de un reconocimiento multicultural del derecho a la diferencia por parte de las "minorías". Un reconocimiento que implica la expresión por parte de estas minorías de su diversidad en cuanto "cultura propia", lo que ha promovido, en gran medida, el vaciamiento del debate estatal sobre el contenido político de esta diversidad, y la marginación de los debates sobre los derechos sociales y políticos que el reconocimiento de estas diversidades internas debiera conllevar.

Lo que hemos observado en el discurso de los integrantes de los movimiento afrodescendientes de Arica es, por otro lado, una conciencia de la necesidad de superar este mismo determinismo cultural. Una necesidad de trascender a formas de lucha que, más que preconizar la validación de la "cultura propia", permita dar paso a un debate político sobre los derechos sociales de las poblaciones afrodescendientes en Chile.

En este sentido, el discurso político de los integrantes de las asociaciones afroariqueñas coincide con ciertas reflexiones críticas de la antropología social postgramsciana. Estas reflexiones vienen abogando en pro de la necesidad de asumir que los procesos culturales, como lo es la emitente constitución de la lucha por una identidad afroariqueña (lucha que inventa a la vez que recupera esta misma identidad), toman forma a partir del entrecruzamiento de "lo cultural" con los procesos de poder. De ahí que autores como Comaroff y Comaroff definan la cultura como:

"El espacio de prácticas significantes, el terreno semántico en el que los seres humanos buscan construir y representar a sí mismo y a los otros -y por ende, la sociedad y la historia-. Como esto sugiere, [la cultura] no es un recipiente de mensajes, un repertorio de signos a ser desplegados a través de una pantalla mental neutral. Ella es forma, a la vez que contenido; nace de la acción así como del pensamiento; es un producto de la creatividad humana así como también de la mímesis; $y$, más allá de todo esto, es empoderada. Pero no es empoderada de la misma manera, o todo el tiempo" (Comaroff y Comaroff 1991: 21-22).36

El poder de acción de un grupo social aparece en este "entrecruzamiento" como una intersección entre las restricciones estructurales (económicas, políticas, e incluso culturales), y la "relativa capacidad de los seres humanos de dar forma a las acciones y percepciones de los demás ejerciendo control sobre la producción, circulación y consumo de los signos y objetos" (Comaroff y Comaroff 1991: 22). Esto sería el poder en su dimensión de agencia, lo que siempre hará referencia al "comando llevado a cabo por los seres humanos en contextos históricos específicos", en los que, normalmente, encontramos un orden hegemónico respecto de cómo lo cultural y la agencia política debieran entenderse. Este orden, que es constituido a modo de la validación de "signos y prácticas, relaciones y distinciones, imágenes y epistemologías -dibujado a partir de un campo cultural históricamente situado- se convierte en algo que se toma por sentado" (Comaroff y Comaroff 1991: 23).37

En gran medida, la recuperación del proceso histórico afroariqueño que aquí presentamos se posiciona en esta comprensión política del entendimiento de la identidad como un fenómeno cultural. Entiende que re-narrar la historia de este campo entre un grupo social y unos discursos

\footnotetext{
${ }^{36}$ Traducción de las autoras.

37 Grimson (2011: 53-67) incide en una postura similar, al asumir la necesidad de politizar la comprensión del concepto de cultura redimensionándolo, simultáneamente, como proceso históricocontextual, y como forma y contenido de un campo hegemónico de poder.
} 
sobre quiénes pertenecen a la nación chilena es imprescindible en el sentido de redimensionar (de desnaturalizar) la lectura hegemónica constituida sobre el papel de Arica y de sus gentes (periféricas y fronterizas) en esta misma nación. Esta lectura hegemónica, en partes, invisibiliza la presencia afro en Chile. Al paso que, también en parte, indaga sobre la posibilidad de que su especificidad cultural pueda venir a ser capitalizada por el Estado y por los mismos colectivos sociales afroariqueños en este momento post-globalización. Y los movimientos afroariqueños dialogan con todas estas posibilidades, lo que se expresa, por ejemplo, en el interés de algunos grupos en potenciar el "patrimonio afroariqueño" como recurso para el turismo cultural internacional en Arica.

Con esto, intentamos comprender la agilidad con que las afiliaciones identitarias pueden jugarse contextualmente de maneras que no solamente sobrepasan, sino que refundan la cultura y lo nacional: dialogando con estas dimensiones sin nunca dejar de limitarse y limitarlas dialécticamente. Es decir, enfatizamos las heterogeneidades históricas particulares que, en la localidad estudiada, motivan posibilidades y formas de acción e identificación que no podrían existir con un mismo sentido y forma en otro espacio (Grimson 2011: 172). Motivan la articulación de unas configuraciones culturales específicas, las cuales podemos entrever en el campo de disputa entre los afroariqueños y el Estado en relación a la determinación de los contenidos culturales y políticos de la etnicidad afrochilena.

Los afrodescendientes, al oponerse al silencio institucional y político sobre su presencia en el territorio nacional que históricamente se impuso desde el Estado chileno, han dado inicio a un proceso de etnicidad que construye a la vez que recupera un sentimiento de pertenencia a una forma de identidad afrodescendiente. El proceso es dialéctico, en el sentido de que ni la identidad es algo dado previamente, ni es algo eminentemente inventado con propósitos políticos. Es en el marco de este movimiento que comprendemos el surgimiento de organizaciones que representan a los afroariqueños y que protagonizaran el proceso de transición en su lucha por el reconocimiento.

Caminamos hacia la comprensión de que la etnicidad, más que una forma dada o natural, conlleva un proceso de transformación etnogénico, constituyendo a la par procesos sociales de identificación y expresando la emergencia de nuevas identidades, asumidas como fundamentales por sus actores, dentro de contextos socioculturales en los que se mantienen fronteras entre grupos percibidos como diferentes. Destacamos así la dimensión e impacto político de estos movimientos de creación, puesto que a partir de ellos "emergen demandas de inclusión en el seno de los Estados-nacionales por parte de los sectores excluidos, cada una de estas demandas, en el nombre de una identidad muchas veces retocada o incluso construida para poder servir de rúbrica al sujeto de esa demanda" (Segato 2007: 15).

La reemergencia étnica o etnogénesis en América Latina, y en especial en una región fronteriza como Arica, involucraría un esfuerzo de relectura de las memorias compactadas o fracturadas, de historias contadas desde un solo lado y que suprimieron otras memorias invisibilizadas por siglos de dominación (Segato 2007). Consecuentemente, el movimiento protagonizado por los grupos afroariqueños en la actualidad conlleva la reconstrucción de los procesos históricos de alteridad vividos en el marco de la experiencia colonial y nacional chilena. Estos fenómenos demandan una mirada que considere que la identidad étnica es dinámica: mutable y reinventada. Debido a los cambios que experimenta y a la historicidad de estos cambios, la etnicidad se constituye de forma flexible y adaptable a las circunstancias. Consecuentemente, más allá de todo esencialismo, la etnicidad está históricamente determinada e imprime una forma política de resignificación del mismo discurso histórico. Lo que también se expresa en algunos movimientos afroariqueños a través de su énfasis en la recuperación de las memorias "de los abuelos" como forma de "encontrar" el principio cohesionador de su identidad étnica.

Esto no quita que las personas, las colectividades e incluso el Estado, vean la etnicidad como algo dado, o que la enuncien así en confrontaciones político-sociales. Existe una tendencia por parte del Estado de reificar la etnicidad, cristalizándola como algo estático, percibiendo los grupos étnicos internos como "sin historia", como "parados en el tiempo". El ejercicio analítico que desarrollamos en el presente artículo sitúa el foco de debate de los contextos actuales afroariqueños en procesos históricos que los anteceden y que, en gran medida, alteran la inter- 
pretación política de la historia presente. Se trata así de apostar por romper la mirada estática sobre los procesos de etnicidad, para comprender las dinámicas políticas que este tipo de proceso implica.
Agradecimientos Trabajo realizado gracias al financiamiento de Becas de Postgrado de la Universidad Católica del Norte y de su Programa de Doctorado en Antropología Social.

\section{$\checkmark$ Referencias citadas}

AGUIRRE, C. 2005. Silencios y ecos: la historia y el legado de la abolición de la esclavitud en Haití y Perú. A Contracorriente 3(1): $1-37$.

APPADURAI, A. 2004. Modernity at Large: Cultural Dimensions of Globalization. University of Minessota Press, Minnesota and London.

APPADURAI, A. 2006. Fear of Small Numbers. An Essay on the Geography of Anger. Duke University Press, Durham and London.

ARAYA, K. 1999. Salvaguardia del patrimonio cultural inmaterial de los afrodescendientes en América Latina. En Informe sobre la situación del PCI afrodescendientes en Chile, UNESCO (Org.), pp.162. CRESPIAL/UNESCO, Santiago de Chile.

ARON, R. 2000. Etapas do pensamento sociológico. Martins Fontes, São Paulo.

ARTAL, N. 2011. A(f)rica: relatos y memorias afro-descendientes en Arica tras la chilenización y el conflicto entre Perú y Chile (1883-1929). Aletheia 2(4): 1-16.

BÁEZ, C. 2012. Lumbanga: memorias orales de la cultura afrochilena. Herco Editores, Arica.

BELLO, A. y M. RANGEL. 2002. La equidad y la exclusión de los pueblos indígenas y afro-descendientes en América Latina y el Caribe. Revista CEPAL 76:39-54.

BOCCARA, G. y P. BOLADOS. 2010. ¿Qué es el multiculturalismo? La nueva cuestión étnica en el Chile neoliberal. Revista de Indias 70(250): 651-690.

BOCCARA, G. e I. SEGUEL-BOCCARA. 2005. Políticas indígenas en Chile (siglos XIX y XX) de la asimilación al pluralismo. El Caso Mapuche. Revista de Indias 217(LIX): 741-774.

BRIONES VALENTÍN, V. 1991. Antecedentes básicos para el estudio histórico de la presencia étnica negra en Arica entre los años 1870 y 1930.
Tesis de licenciatura en Historia y Geografía. Universidad de Tarapacá, Arica.

BRIONES VALENTÍN, V. 2004. Arica colonial: libertos y esclavos negros entre el Lumbanga y las Maytas. Chungara 36: 813-816.

BUTLER, K. D. 2000. From Black History to Diasporan History: Brazilian Abolition in Afro-Atlantic Context. African Studies Review 43(1): 129-139.

CÁCERES, R. G. 2001. Prólogo. En Rutas de la esclavitud en África y América Latina, Rina Gómez Cáceres (Ed.), pp. 9-17. Editorial Universidad de Costa Rica, San José.

CAIRATI, E. 2011. AfroPerú: Tras las huellas de la negritud en el Perú. Otras Modernidades 6(11): 121-138.

CASAÚS-ARZÚ, M. E. 2006. La verdadera magnitud del racismo: ensayo para una definición y algunas consideraciones. Puntos de Vista II(6): 7-29.

CHARÚN-ILLESCAS, L. 2001. Malambo. Editorial Universidad Nacional Federico Villarreal, Lima.

COMAROFF, J. L. y J. COMAROFF. 1991. Of Revelation and Revolution: Christianity, colonialism, and consciousness in South Africa. University of Chicago Press, Chicago and London.

COMAROFF, J. L. yJ. COMAROFF. 1992. Ethnography and the historical imagination. Westview Press, Boulder.

COMAROFF, J. L. y J. COMAROFF. 2011. Etnicidad S.A. Katz Editores, Madrid.

CORPORACIÓN PARTICIPA. 2012. Uso de la ley de transparencia para la inclusión de la etnia afro-descendiente en el censo chileno. Corporación Participa, Santiago de Chile.

CORTÉS, V. 1963. La trata de esclavo durante los primeros descubrimientos (1489-1515). Anuario de Estudios Atlánticos 9: 23-49. 
DÍAZ ARAYA, A. 2010. Arica siglo XX. Historia y Sociedad en el extremo norte de Chile. Ediciones Universidad de Tarapacá, Arica.

DEL CANTO LARIOS, G. 2003. Oro Negro: una aproximación a las comunidades afro-descendientes en la ciudad de Arica y el Valle de Azapa. Editorial Semejanza, Santiago de Chile.

DUSSEL, E. 1994. 1492. El encubrimiento del Otro. Hacia el origen del mito de la modernidad. Plural editores/Centro de Información para el Desarrollo, La Paz.

ELTIS, D. 2001. The Volume and Structure of the Transatlantic Slave Trade: A Reassessment. The William and Mary Quarterly 58(1): 17-46.

FABIAN, J. 2007. Memory against Culture. Arguments and Reminders. Duke University Press, Durham and London.

FABIAN, J. 2014. Time and the other: How anthropology makes its object. Columbia University Press, New York.

FAUSTO, B. 1995. Brasil, de colonia a democracia. Alianza Editorial, Madrid.

FONTAINE, P. M. 1980. Research in the Political Economy of Afro-Latin America. Latin American Research Review 15 (2): 111-141.

GALECIO, B. 2011. Patrimonio Arquitectónico del sector de Molle Pampa, Valle de Lluta: Elaboración de dos Expedientes Técnicos para declaración de Monumentos Históricos. Informe Casa Criadero de Esclavos. PROYECTO No9888-4, FONDART Regional, Arica.

GILROY, P. 2002. The Black Atlantic. Modernity and Double Consciussness. Verso, London.

GONZÁLEZ CASANOVA, P. 2003. Colonialismo Interno (una redefinición). Revista Rebeldía 12: 1-31.

GONZÁLEZ MIRANDA, S. 2008. La llave y el candado. El conflicto entre Perú y Chile por Tacna y Arica (1883-1929). LOM ediciones, Santiago de Chile.

GORDON, E. T. y M. ANDERSON. 1999. The African Diaspora: Toward an Ethnography of Diasporic Identification. The Journal of American Folklore 112(445): 282-296.

GRIMSON, A. 2011. Los límites de la cultura. Crítica de las teorías de la identidad. Siglo XXI, Buenos Aires.

GROSFOGUEL, R. 2006. La descolonización de la economía política y los estudios postcoloniales: transmodernidad, pensamiento fronterizo y colonialidad global. Notas de Población 80: 53-74.
GUNDERMANN, H., J.I. VERGARA y R. FOERSTER. 2005. Contar a los indígenas en Chile: Autoadscripción étnica en la experiencia censal de 1992 y 2002. Estudios Atacameños 30: 91-113.

GUNDERMANN, H. y J. I. VERGARA. 2009. Comunidad, organización y complejidad social andinas en el norte de Chile. Estudios Atacameños 38: 107-126.

HASTINGS, A. 2000 . La construcción de las nacionalidades. Cambridge University Press, Cambridge y Madrid.

HOBSBAWM, E. 1997. Naciones y nacionalismos desde 1780. Crítica, Barcelona.

HOBSBAWM, E. y T. RANGER. 1984. Introduction: Inventing traditions. En The invention of tradition, E. Hobsbawm y T. Ranger (Eds.), pp.1-14. Cambridge University Press, London and New York.

IANNI, O. 1978. Escrauiddo e racismo. Editora HUCITEC, São Paulo.

KLEIN, H. S. 2010. The Atlantic slave trade. Cambridge University Press, Cambridge.

KYMLICKA, W. 1995.Multicultural Citizenship. University of Oxford Press, Oxford and New York.

LEVINE, R. M. 1989. Review: 'Turning on the Lights': Brazilian Slavery Reconsidered One Hundred Years after Abolition. Latin American Research Review 24(2): 201-217.

LÍBANO-SOARES, C. E. 2002. A Capoeira escrava e outras tradições rebeldes no Rio de Janeiro (1808 - 1850). Editora Unicamp, Campinas.

LOVEJOY, P. E. 1982. The Volume of the Atlantic Slave Trade: A Synthesis. The Journal of African History 23(4): 473-501.

MALDONADO-TORRES, N. 2007. Sobre la colonialidad del ser: contribuciones al desarrollo de un concepto. En El giro decolonial. Reflexiones para una diversidad epistémica más allá del capitalismo global, S. Castro-Gómez y R. Grosfoguel (Eds.), pp.127-167. IESCO/Siglo del Hombre, Bogotá

MARX, K. 1996. A assim chamada Acumulação Primitiva. En $O$ Capital, Karl Marx, vol. II, pp.338-382. Editora Nova Cultural, São Paulo.

NARVÁEZ, M. 2008. Rescate de la cultura afro descendiente en el Valle de Azapa. Tesis de técnico en Turismo. Instituto Profesional Los Leones, Santiago de Chile. 
PAREKH, B. (2000). Rethinking Multiculturalism. Cultural Diversity and Political Theory. Macmillan Press, Houdmills, Basingstoke, Hampshire y Londres.

PATTERSON, R. T. y R. D. G. KELLEY. 20oo. Unfinished Migrations: Reflections on the African Diaspora and the Making of the Modern World. African Studies Review 43(1): 11-45.

PODESTÁ ARZUBIAGA, J. 2011. Regiones fronterizas y flujos culturales: La peruanidad en una región chilena. Universum 1(26): $123-137$.

RESTREPO, E. 2004. Biopolítica y alteridad: dilemas de la etnización de las colombias negras. En Conflicto e (in)visibilidad. Retos en los estudios de la gente negra en Colombia, E. Restrepo, y A. Rojas (Eds.), pp.271-299. Editorial Universidad del Cauca, Popayán y Cali.

RIVERA, C. y C. RUBIO. 2012. Análisis crítico de los instrumentos de protección y su aplicación a las comunidades de afrodescendientes en Chile. Tesis de licenciatura en Derecho. Facultad de Ciencias Sociales y Jurídicas. Universidad de Tarapacá, Arica.

ROMÁN, R. M. 2010. Discurso informativo y luchas por el reconocimiento: el "conflicto mapuche" en El Mercurio y La Segunda (Chile, 2008-2009). Perspectivas de la Comunicación 3(2): $29-47$.

RUSSELL-WOOD, A. J. R. 1978. Iberian Expansion and the Issue of Black Slavery: Changing Portuguese Attitudes, 1440-1770. The American Historical Review 83(1):16-42.

SAN MARTIN, W. A. 2007. Esclavitud, libertad, libertades y resistencias. Hacia una propuesta integrativa a las condiciones de la negritud en Chile, Siglo XVIII. Summa Historiae, Revista de Estudios Latinoamericanos 2: 195-209.

SALGADO, M.Afrochilenos. Una historia oculta. FNDR, Arica.

SEGATO, R. L. 1999. Identidades políticas/Alteridades históricas: una crítica a las certezas del pluralismo global. Maguaré 14: 114-147.

SEGATO, R. L. 2007. La nación y sus Otros: raza, etnicidad y diversidad religiosa en tiempos de politicas de la identidad. Prometeo Libros, Buenos Aires.

SIERRA, L. 2003. La Constitución y los indígenas en Chile: reconocimiento individual y no colectivo. Estudios Públicos 92: 19-27.

STEFONI, C. 2005. Inmigrantes Transnacionales. La formación de comunidades y la transformación en ciudadanos. En El quinto suyo. Transnacionalidady formación diaspórica en la migración peruana, U. D. Berg y K. Paerregaard (Eds.), pp.261-289. Instituto de Estudios Peruanos, Lima.

SUTCLIFFE, B. 1998. Nacido en otra parte. Un ensayo sobre la migración internacional, el desarrollo y la equidad. Hegoa, Bilbao.

URQUHART, J. 2008. Afrodescendientes en Arica hoy. Tesis de magíster en Ciencias de la Comunicación. Universidad de Tarapacá, Arica.

VERGARA, J. I. y R. FOERSTER. 2002. Permanencia y transformación del conflicto Estado-mapuches en Chile. Revista Austral Ciencias Sociales (6): 35-46.

WALKER, S. 2010. Conocimiento desde adentro. Los afro-sudamericanos hablan de sus pueblos y sus historias. Fundación Pedro Andavérez Peralta, Afrodiáspora, Fundación Interamericana, OCCDP y PIEB, La Paz.

WALLERSTEIN, E. 2006. Análisis de sistemas-mundo: una introducción. Ed. Siglo XXI, Ciudad de México.

WALSH, B. 2004. Colonialidad, conocimiento y diáspora afroandina: construyendo etnoeducación e interculturalidad en la universidad. En Conflicto e (in)visibilidad. Retos en los estudios de la gente negra en Colombia, E. Restrepo y A. Rojas (Eds.), pp.331-348. Editorial Universidad del Cauca, Popayán y Cali.

WHITTEN, N. E. y N. S. D. FRIEDEMANN. 1974. La cultura negra del litoral ecuatoriano y colombiano: un modelo de adaptación étnica. Revista colombiana de antropología 17: 75-115.

WORMALD, A. 1966 [1903]. El mestizo en el departamento de Arica. Anales de la Universidad del Norte 5: 183-318.

YELVINGTON, K. A. 2001. The Anthropology of Afro-Latin America and the Caribbean: Diasporic Dimensions. Annual Review of Anthropology 30: 27-260.

\section{Páginas web:}

WWW.UTA.CL. 2013. Lanzamiento del libro "Afrochilenos, una historia oculta". En: http://www.uta.cl/lanzamiento-del-libroafrochilenos-una historia-oculta-se-realizo-en-la-bibliotecacentral-de-la-uta/web/2013-07-12/085220.html. Consultada el 12 de julio de 2013 . 